Electronic Supporting Information:

\title{
Colossal Trellis-Like Single-Crystal to Single-Crystal Structural Transformations in Two 1D Coordination Polymers
}

Lisa M. van Wyk and Leonard J. Barbour ${ }^{*}$

Department of Chemistry and Polymer Science, University of Stellenbosch, 7602 Matieland, South Africa.

* Correspondence to Professor Leonard J. Barbour (Email: lib@sun.ac.za) 


\section{Contents}

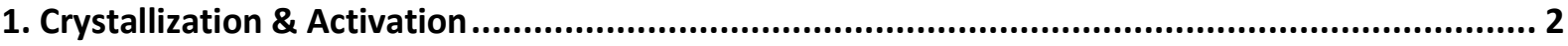

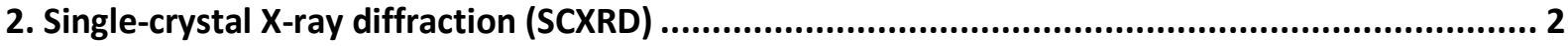

3. Fourier transform infrared spectrophotometry (FT-IR) ............................................................ 8

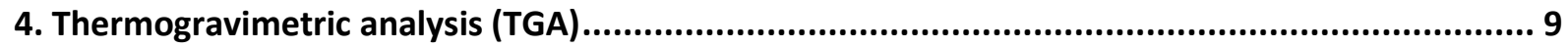

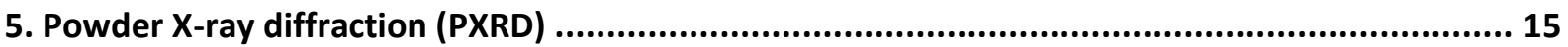

6. Pressure Gradient Differential Scanning Calorimetry (PG-DSC) ........................................... 17

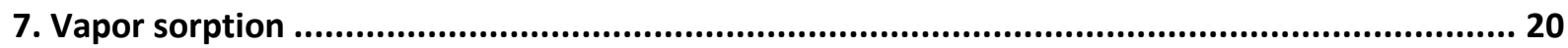

8. Vapor pressures and kinetic diameters of select solvents........................................................ 22

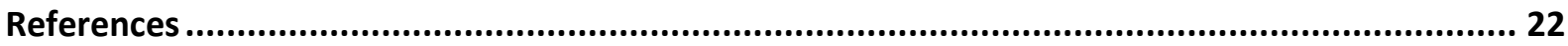




\section{Crystallization \& Activation}

\subsection{Crystallization of 1}

$\{[\mathrm{Zn}(\mathrm{bpdc})(\mathrm{bpy})] \cdot 2 \mathrm{DMF}\}_{n}$ (1) was prepared solvothermally. In a scintillation vial, equimolar amounts of the ligands 4,4'-biphenyldicarboxylic acid (bpdc, $0.30 \mathrm{mmol}, 72.7 \mathrm{mg}$ ) and 2,2'-bipyridine (bpy, $0.30 \mathrm{mmol}, 46.9 \mathrm{mg})$, along with $\mathrm{Zn}\left(\mathrm{NO}_{3}\right)_{2} \cdot 6 \mathrm{H}_{2} \mathrm{O}(0.40 \mathrm{mmol}, 119.4 \mathrm{mg})$ were added to $5 \mathrm{ml} \mathrm{DMF}$ and sonicated until partially dissolved. The vial was placed in an $80{ }^{\circ} \mathrm{C}$ preheated oven for $4-7$ days. Clear, rod-shaped crystals were produced in a quantitative yield.

\subsection{Activation of 1}

Crystals of 1 were activated in a thermogravimetry furnace $\left(T_{\max }=180{ }^{\circ} \mathrm{C}\right.$, ramp rate $=$

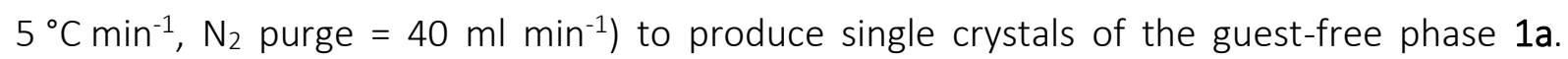
Where single crystals of 1 a were not required supercritical $\mathrm{CO}_{2}$ drying may be used (see $\S 1.4$.$) .$

\subsection{Crystallization of 2}

$\{[\mathrm{Zn}(\mathrm{bdc})(\mathrm{bpy})] \cdot \mathrm{DMF}\}_{n}$ (2) was prepared solvothermally. In a scintillation vial, equimolar amounts of the ligands 1,4-benzenedicarboxylic acid (bdc, $0.1 \mathrm{mmol}, 16.6 \mathrm{mg}$ ) and 2,2'-bipyridine (0.1 mmol, $15.6 \mathrm{mg})$, in addition to $\mathrm{Zn}\left(\mathrm{NO}_{3}\right)_{2} \cdot 6 \mathrm{H}_{2} \mathrm{O}(0.15 \mathrm{mmol}, 44.8 \mathrm{mg})$ were added to $3 \mathrm{ml} \mathrm{DMF}$ and sonicated until partially dissolved. The scintillation vial containing the reaction mixture was then placed in a preheated oven at $80{ }^{\circ} \mathrm{C}$ for $4-7$ days. The crystallization produced clear plates formed in a quantitative yield.

\subsection{Activation of 2}

Crystals of 2 were activated by supercritical $\mathrm{CO}_{2}$ drying $\left(\mathrm{T}=40{ }^{\circ} \mathrm{C}, \mathrm{P} \approx 100\right.$ bar, $\mathrm{t} \approx 4-6$ hours $)$ to produce single crystals of the guest-free phase $2 a$. Supercritical drying was carried out using a Tousimis ${ }^{\mathrm{TM}}$ Samdri ${ }^{\circledR}$ PVT-3D critical point dryer.

\section{Single-crystal X-ray diffraction (SCXRD)}

Crystals of appropriate size possessing suitable morphology and ability to extinguish plane-polarized light were mounted onto the tip of a MiTeGen loop ${ }^{1}$ using Paratone ${ }^{\circledR} \mathrm{N}$ oil. The mounted crystal was then placed on a goniometer head attached to a diffractometer. X-ray intensity data were recorded on a Bruker APEX I| DUO or a Bruker D8 Venture diffractometer. The DUO instrument is equipped with an Incoatec I $\mu$ S molybdenum $(\lambda=$ 
$0.71073 \AA$ ) microfocus $X$-ray source and a CCD area detector. The Venture instrument is equipped with an Incoatec I $\mu$ S 3.0 molybdenum $(\lambda=0.71073 \AA)$ microfocus $X$-ray source and a Photon II CPAD detector. All diffractometers are fitted with an Oxford Cryosystems cryostat (700 Series Cryostream Plus for the DUO instrument and 800 Series Cryostream Plus for the Venture instrument), which is used to control the sample temperature. Both the frame exposure time and the number of frames collected for each experiment were varied depending on the diffraction quality and characteristics of the mounted crystal.

Data reduction and absorption corrections were carried out using the SAINT ${ }^{2}$ and SADABS 3 programs, respectively. Unit-cell dimensions were refined on all data and space groups were assigned based on systematic absences and intensity statistics. The structures were solved with a dual-space algorithm or direct methods using SHELXT ${ }^{4}$ or SHELXS-2016/1, ${ }^{5}$ respectively. Structure refinement was carried out with SHELXL-2018/15 using the X-Seed ${ }^{6,7}$ graphical user interface. Non-hydrogen atoms were refined anisotropically. Hydrogen atoms were placed in calculated positions. Illustrations of all crystal structures were generated using the program POV-Ray ${ }^{8}$ and Mercury. ${ }^{9-11}$ 
Table S1. Crystallographic parameters for both the as-synthesized and activated species.

\begin{tabular}{|c|c|c|c|c|}
\hline & 1 & $1 a$ & 2 & $2 a$ \\
\hline Empirical Formula & $\mathrm{C}_{30} \mathrm{H}_{30} \mathrm{~N}_{4} \mathrm{O}_{6} \mathrm{Zn}$ & $\mathrm{C}_{24} \mathrm{H}_{16} \mathrm{~N}_{2} \mathrm{O}_{4} \mathrm{Zn}$ & $\mathrm{C}_{21} \mathrm{H}_{19} \mathrm{~N}_{3} \mathrm{O}_{5} \mathrm{Zn}$ & $\mathrm{C}_{18} \mathrm{H}_{12} \mathrm{~N}_{2} \mathrm{O}_{4} \mathrm{Zn}$ \\
\hline $\begin{array}{l}\text { Formula weight } \\
\qquad\left(\mathrm{g} \mathrm{mol}^{-1}\right)\end{array}$ & 607.94 & 461.76 & 458.77 & 385.67 \\
\hline Temperature $(\mathrm{K})$ & $100(2)$ & $100(2)$ & $100(2)$ & $100(2)$ \\
\hline Wavelength ( $\AA$ ) & 0.71073 & 0.71073 & 0.71073 & 0.71073 \\
\hline Crystal system & Monoclinic & Monoclinic & Monoclinic & Monoclinic \\
\hline Space group & $P 2_{1} / n$ & $P 2_{1} / n$ & $P 2_{1} / c$ & $P 2_{1} / c$ \\
\hline$a(\AA)$ & $7.598(1)$ & $7.700(4)$ & $7.362(1)$ & $7.638(4)$ \\
\hline$b(\AA)$ & $26.508(5)$ & $17.546(9)$ & $23.320(4)$ & $20.447(10)$ \\
\hline$c(\AA)$ & $16.115(3)$ & $14.651(8)$ & $12.285(2)$ & $10.566(5)$ \\
\hline$\alpha\left(^{\circ}\right)$ & 90 & 90 & 90 & 90 \\
\hline$\beta\left(^{\circ}\right)$ & $99.22(3)$ & $100.10(1)$ & $95.159(3)$ & $95.873(7)$ \\
\hline$\gamma\left({ }^{\circ}\right)$ & 90 & 90 & 90 & 90 \\
\hline$V\left(\AA^{3}\right)$ & 3204.0(11) & 1948.7(18) & $2100.5(6)$ & 1641.3(14) \\
\hline Z & 4 & 4 & 4 & 4 \\
\hline Calculated density / $\left(\mathrm{g} \mathrm{cm}^{-3}\right) \ddagger$ & 0.957 & 1.574 & 1.220 & 1.561 \\
\hline $\begin{array}{l}\text { Absorption coefficient } \\
\qquad\left(\mathrm{mm}^{-1}\right)\end{array}$ & 0.788 & 1.296 & 1.189 & 1.522 \\
\hline$F_{000}$ & 944.0 & 944.0 & 784.0 & 784.0 \\
\hline$\theta$ range for data collection $\left({ }^{\circ}\right)$ & $2.00-28.38$ & $1.83-25.10$ & $1.75-26.43$ & $1.99-25.04$ \\
\hline Miller index ranges & $\begin{array}{l}-10 \leq h \leq 10 \\
-35 \leq k \leq 35 \\
-21 \leq l \leq 21\end{array}$ & $\begin{aligned}-9 & \leq h \leq 9 \\
-20 & \leq k \leq 20 \\
-17 & \leq 1 \leq 17\end{aligned}$ & $\begin{aligned}-9 & \leq h \leq 9 \\
-29 & \leq k \leq 29 \\
-15 & \leq 1 \leq 15\end{aligned}$ & $\begin{aligned}-9 & \leq h \leq 9 \\
-24 & \leq k \leq 24 \\
-12 & \leq l \leq 12\end{aligned}$ \\
\hline Reflections collected & 85516 & 14393 & 28904 & 12597 \\
\hline Independent reflections & 8016 & 3464 & 4296 & 2897 \\
\hline Completeness to $\theta_{\max }(\%)$ & 99.8 & 99.7 & 99.5 & 99.8 \\
\hline Max. and min. transmission & $0.746,0.700$ & $0.745,0.597$ & $0.745,0.571$ & $0.745,0.565$ \\
\hline Refinement Method & $\begin{array}{c}\text { Full-matrix } \\
\text { least-squares } \\
\text { on } F^{2}\end{array}$ & $\begin{array}{c}\text { Full-matrix } \\
\text { least-squares } \\
\text { on } F^{2}\end{array}$ & $\begin{array}{c}\text { Full-matrix } \\
\text { least-squares } \\
\text { on } F^{2}\end{array}$ & $\begin{array}{c}\text { Full-matrix } \\
\text { least-squares } \\
\text { on } F^{2}\end{array}$ \\
\hline Data / restraints / parameters & $\begin{array}{c}8016 / 1837 / \\
552\end{array}$ & 3464 / 6 / 280 & $4296 / 30 / 226$ & $2897 / 0 / 226$ \\
\hline Goodness-of-fit on $F^{2}$ & 1.020 & 1.024 & 1.002 & 1.204 \\
\hline Final $R$ indices $[I>2 \sigma(I)]$ & $\begin{array}{c}R 1=0.0405 \\
W R 2=0.1040\end{array}$ & $\begin{array}{c}R 1=0.0718 \\
w R 2=0.1420\end{array}$ & $\begin{array}{c}R 1=0.0396 \\
W R 2=0.1074\end{array}$ & $\begin{array}{c}R 1=0.0809 \\
w R 2=0.1558\end{array}$ \\
\hline
\end{tabular}

$\ddagger$ Densities calculated with structures that have had the guest electron density removed by the Platon/SQUEEZE ${ }^{12}$ routine 


\subsection{In situ single-crystal to single-crystal activation of 1}

To critically assess whether this was in fact a single-crystal to single-crystal transformation, activation of a crystal of 1 was carried out in situ on a Bruker D8 Venture diffractometer. After first determining the specific unit-cell parameters for the as-synthesized crystal ( $270 \mathrm{~K}$, Table S2) it was heated on the diffractometer to $435 \mathrm{~K}$ at a rate of $120 \mathrm{~K} \mathrm{~h}^{-1}$, held at this temperature for 180 seconds and then cooled to $270 \mathrm{~K}$ at $120 \mathrm{~K} \mathrm{~h}^{-1}$. A full data collection was carried out on the now activated crystal (form 1a). The unit-cell parameters for both forms are shown in the table below.

Table S2. Selected crystallographic parameters for the in situ activation of 1 to 1 a.

\begin{tabular}{|c|c|c|}
\hline & 1 & 1a_insitu \\
\hline Temperature/K & $270(2)$ & $270(2)$ \\
Wavelength/ $\AA$ & 0.71073 & 0.71073 \\
Crystal system & Monoclinic & Monoclinic \\
Space group & not determined & $P 21 / n$ \\
$\boldsymbol{a} / \AA$ & 7.69 & $7.852(1)$ \\
$\boldsymbol{b} / \AA$ & 26.14 & $17.583(4)$ \\
$\boldsymbol{c} / \AA$ & 16.65 & $14.848(3)$ \\
$\boldsymbol{\alpha} /{ }^{\circ}$ & 90 & 90 \\
$\boldsymbol{\beta} /^{\circ}$ & 99.48 & $101.21(1)$ \\
$\boldsymbol{\gamma} /^{\circ}$ & 90 & 90 \\
$\mathrm{~V} / \AA^{3}$ & 3300 & $2010.9(7)$ \\
\hline
\end{tabular}

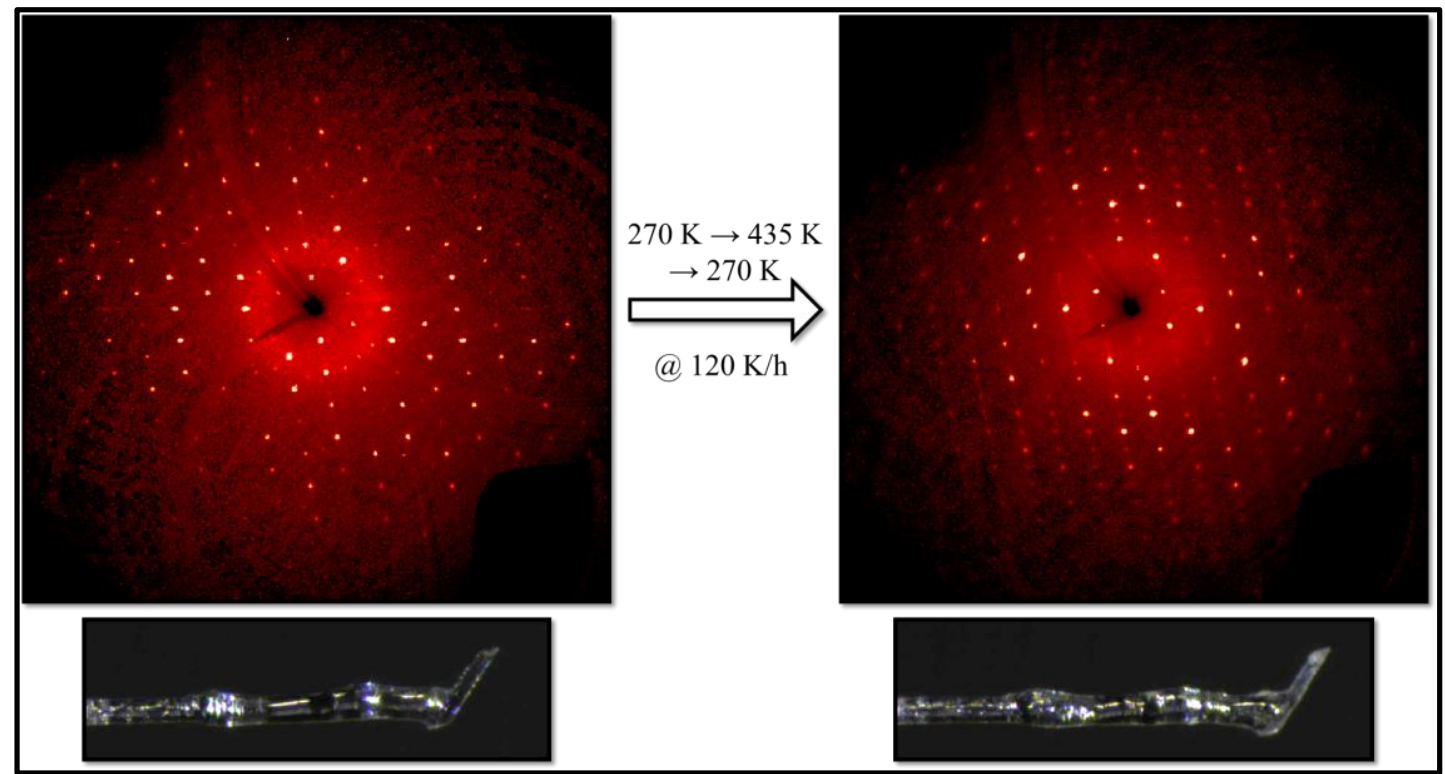

Figure S1. Precession images and photographs of the in situ activation of a crystal of 1 (left) to 1a (right). Precession images show the $h 0 /$ plane. 
Table S3. Change in the crystal size before and after in situ activation of a two single crystals of 1.

\begin{tabular}{|c|c|c|c|c|}
\hline & \multicolumn{2}{|c|}{ Crystal 1 } & \multicolumn{2}{c|}{ Crystal 2 } \\
\cline { 2 - 4 } & 1 & $1 \mathrm{a}$ & 1 & $1 \mathrm{a}$ \\
\hline Crystal size min (mm) & 0.060 & 0.040 & 0.084 & 0.055 \\
Crystal size mid (mm) & 0.085 & 0.089 & 0.172 & 0.191 \\
Crystal size max (mm) & 0.321 & 0.291 & 0.254 & 0.208 \\
Crystal volume (mm $\left.{ }^{3}\right)$ & 0.00164 & 0.00104 & 0.00367 & 0.00219 \\
Change in crystal volume (\%) & - & 37 & - & 40 \\
\hline
\end{tabular}

\subsection{Probe-Accessible Volume (PAV) maps}

The PAV ${ }^{13}$ for each species was investigated in Mercury ${ }^{9-11}$ using a probe radius of $1.5 \AA$ and a grid spacing of $0.2 \AA$.

(a) 1 (major component)

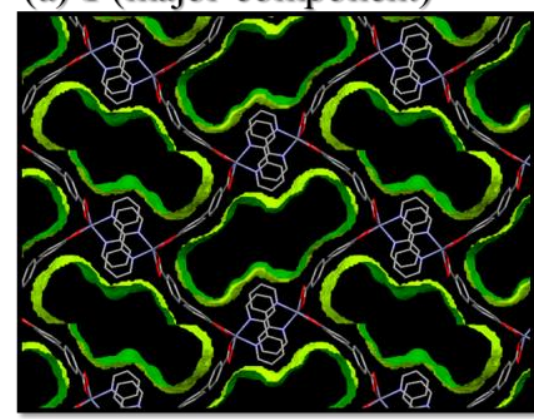

[100] (b) 1 (minor component)

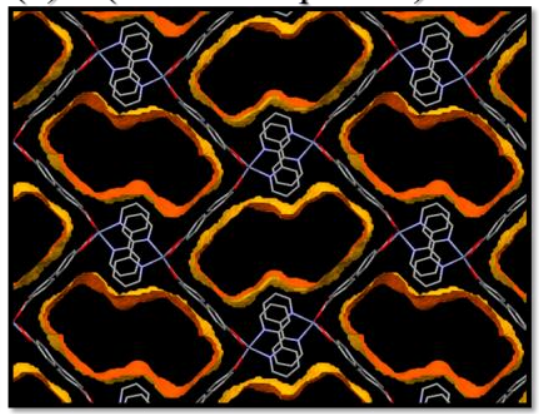

[100] (c) 2

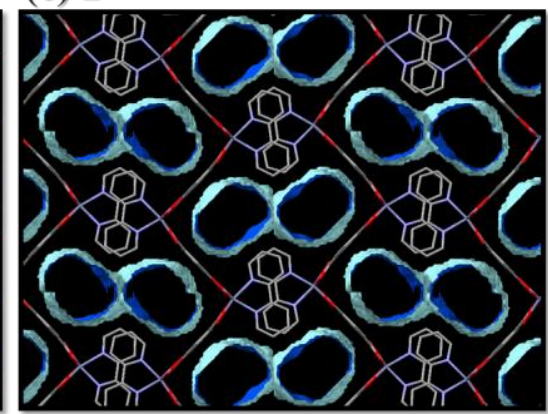

[100]

Figure S2: PAV of 1 with only the (a) major or (b) minor component of bpdc disorder present ( 45 and $46 \%$ SAS, respectively) and (c) $2(32 \%$ PAV). In (a) and (b) only the major component of the bpy disorder is shown. Hydrogen atoms are omitted for clarity.

\subsection{Comparison of the asymmetric units of the as-synthesized and activated materials,} and the ensuing Cambridge Structural Database (CSD $)^{14}$ search.
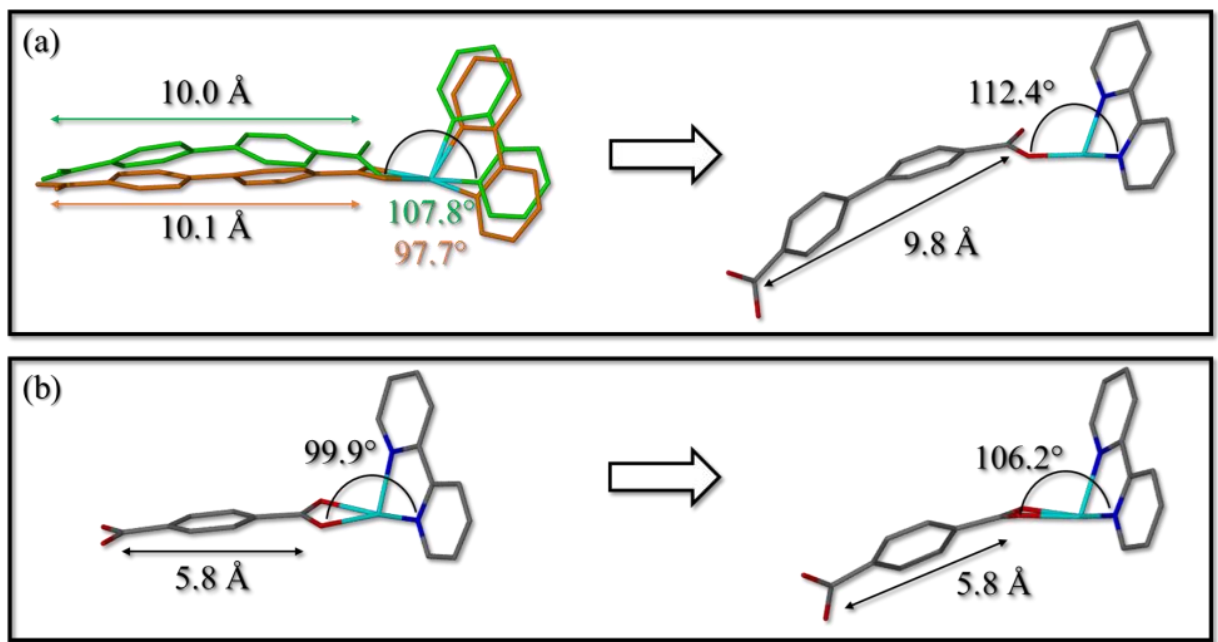

Figure S3. Comparison of the asymmetric units (ASUs) of the as-synthesized (left) and activated forms (right) of 1/1a (a) and 2/2a (b). In (a) the ligand disorder in 1 shows the major component (for both bpdc and bpy disorder) in green and the minor component in orange. This coloring scheme is reflected in the individual measurements as well. For all ASUs hydrogen atoms are omitted for clarity. 

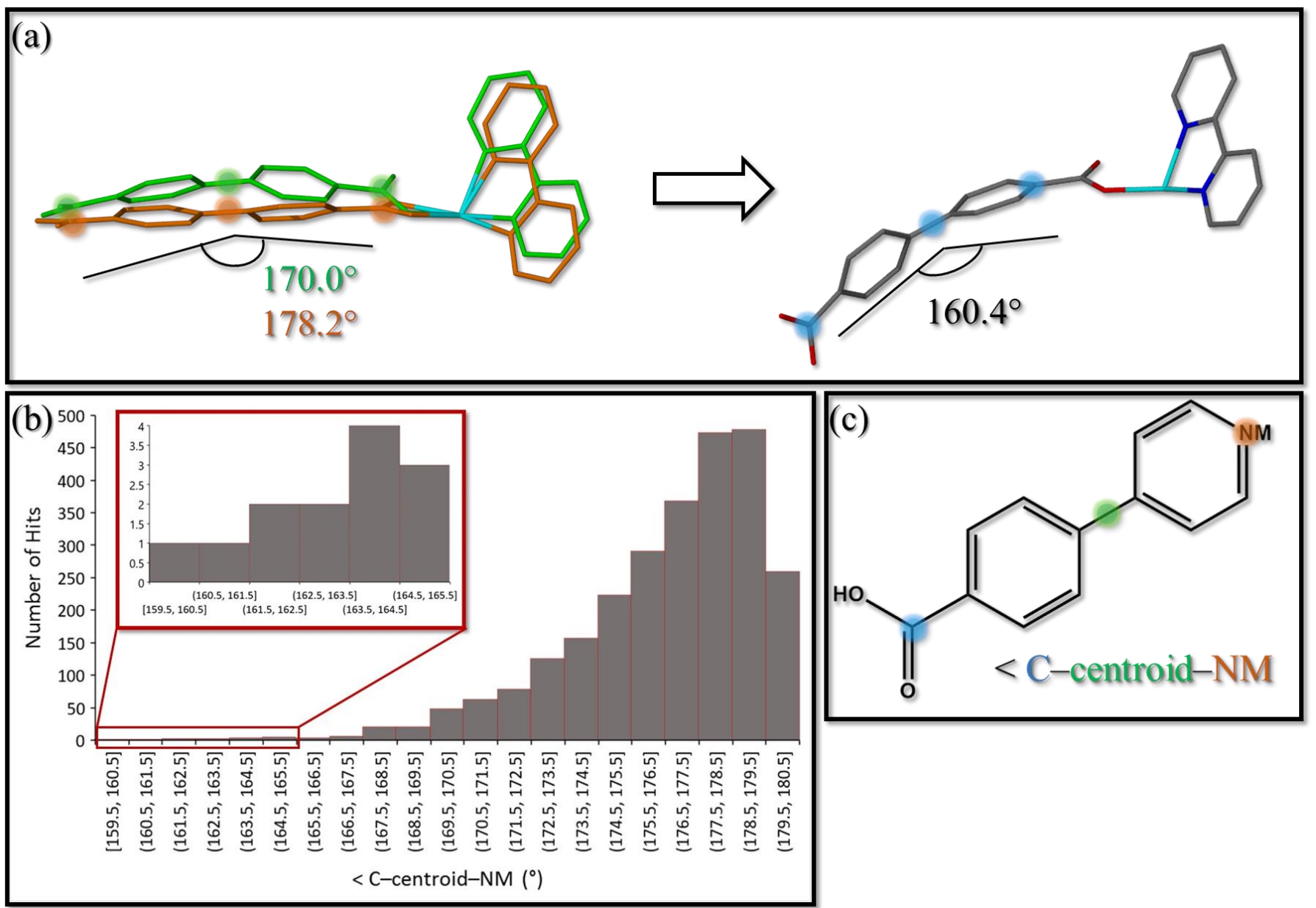

Figure S4. The change in bending angle of the bpdc ligand in 1 (left) and 1a (right), measured as: carboncentroid-carbon, is shown in (a). In (a) the ligand disorder in 1 shows the major component (for both bpdc and bpy disorder) in green and the minor component in orange. This coloring scheme is reflected in the individual measurements as well. For all ASUs in (b) hydrogen atoms are omitted for clarity. A search of comparative bending angles in similar ligands was carried out in the CSD the results of which are shown as histograms in (b), with the search criterion shown in (c). The search criteria defined the angle between the carboxylate carbon, a centroid between the phenyl ring and any para positioned non-metal (NM). Note that multiple hits may originate from a single structure.

Please note that although there is one reported structure where the bending angle exceeds that within this work, this angle is in actuality the result of disorder and thus not a real angle, but an artefact of the modelling of the disorder (CSD refcode: BAJYES).

Table S4. Descriptive statistics for the CSD searches carried out for comparative bending angles in similar ligands. Note that multiple hits may originate from a single structure.

\begin{tabular}{|c|c|c|}
\hline & entire CSD & $\begin{array}{c}\text { only angles } \\
155 \mathbf{s}^{\circ} \leq 165\end{array}$ \\
\hline Number of hits & 2630 & 13 \\
Minimum & 159.52 & 159.52 \\
Maximum & 180 & 164.95 \\
Mean & 176.53 & 163.10 \\
Median & 177.26 & 163.67 \\
Lower quantile & 175.11 & 162.17 \\
Upper quantile & 178.66 & 164.47 \\
\hline
\end{tabular}




\section{Fourier transform infrared spectrophotometry (FT-IR)}

IR spectra were recorded using a Bruker Alpha P ATR-IR instrument. A background measurement was performed before each experimental spectrum was recorded.

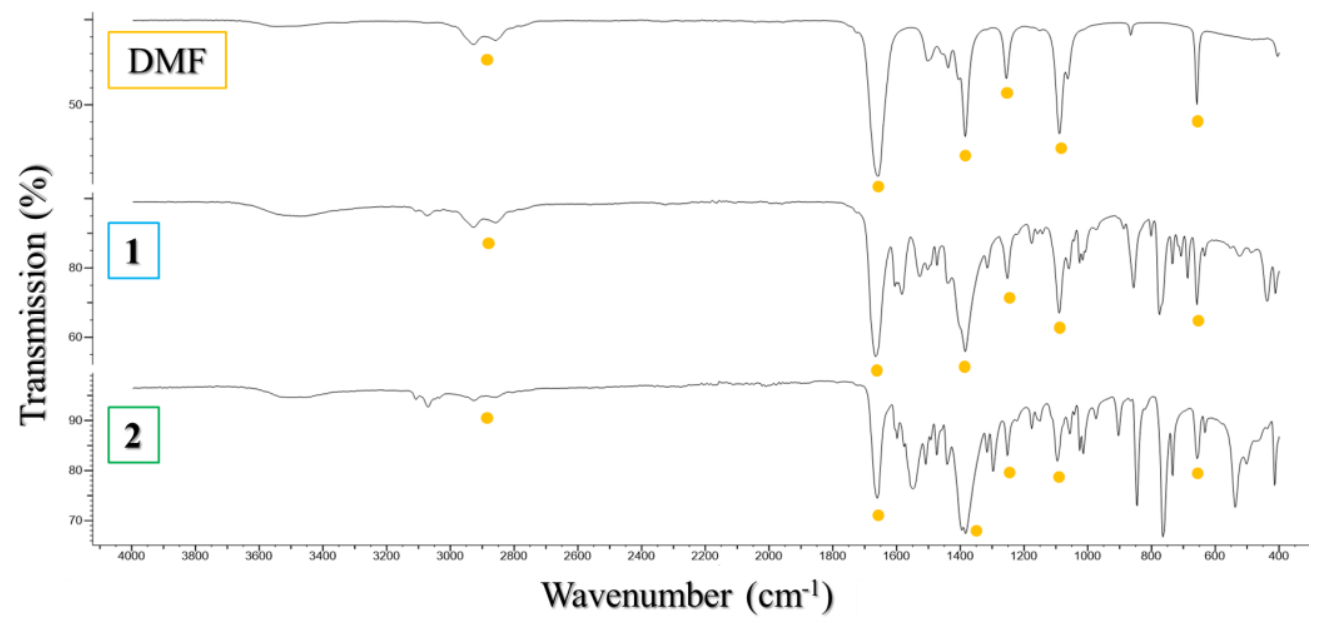

Figure S5. IR spectra of neat DMF (top), 1 (middle) and 2 (bottom). Yellow dots indicate characteristic peaks of DMF.

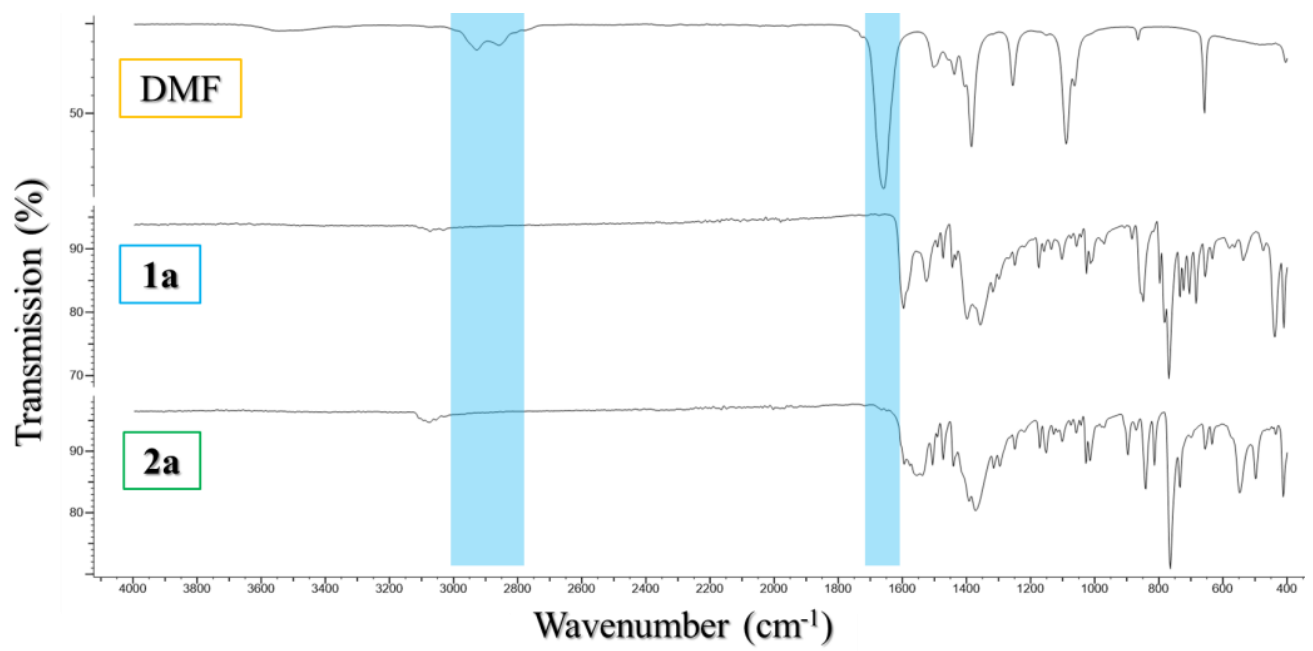

Figure S6. IR spectra of neat DMF (top), 1a (middle) and $2 a$ (bottom). Blue areas indicate the loss the characteristic peaks of DMF (sp ${ }^{3} \mathrm{C}-\mathrm{H}$ and $\mathrm{C}=\mathrm{O}$ stretches at $\mathrm{ca} 2900$ and $1650 \mathrm{~cm}^{-1}$, respectively, both vanish). 


\section{Thermogravimetric analysis (TGA)}

A TGA trace was generated by measuring the percentage mass as the sample was heated at a constant rate. A TA Instruments Q500 thermogravimetric analyzer was used. Samples were contained in aluminum pans and sample weights typically ranged from 1 to $5 \mathrm{mg}$. $\mathrm{N}_{2}$ gas (flow rate $40 \mathrm{ml} \mathrm{min}-1$ ) was used to purge the furnace. The temperature was ramped from room temperature to $\mathrm{ca} .600{ }^{\circ} \mathrm{C}$ at a constant heating rate of $10{ }^{\circ} \mathrm{C} \mathrm{min}-1$. The resulting thermograms were analyzed using the TA Instruments Universal Analysis program.

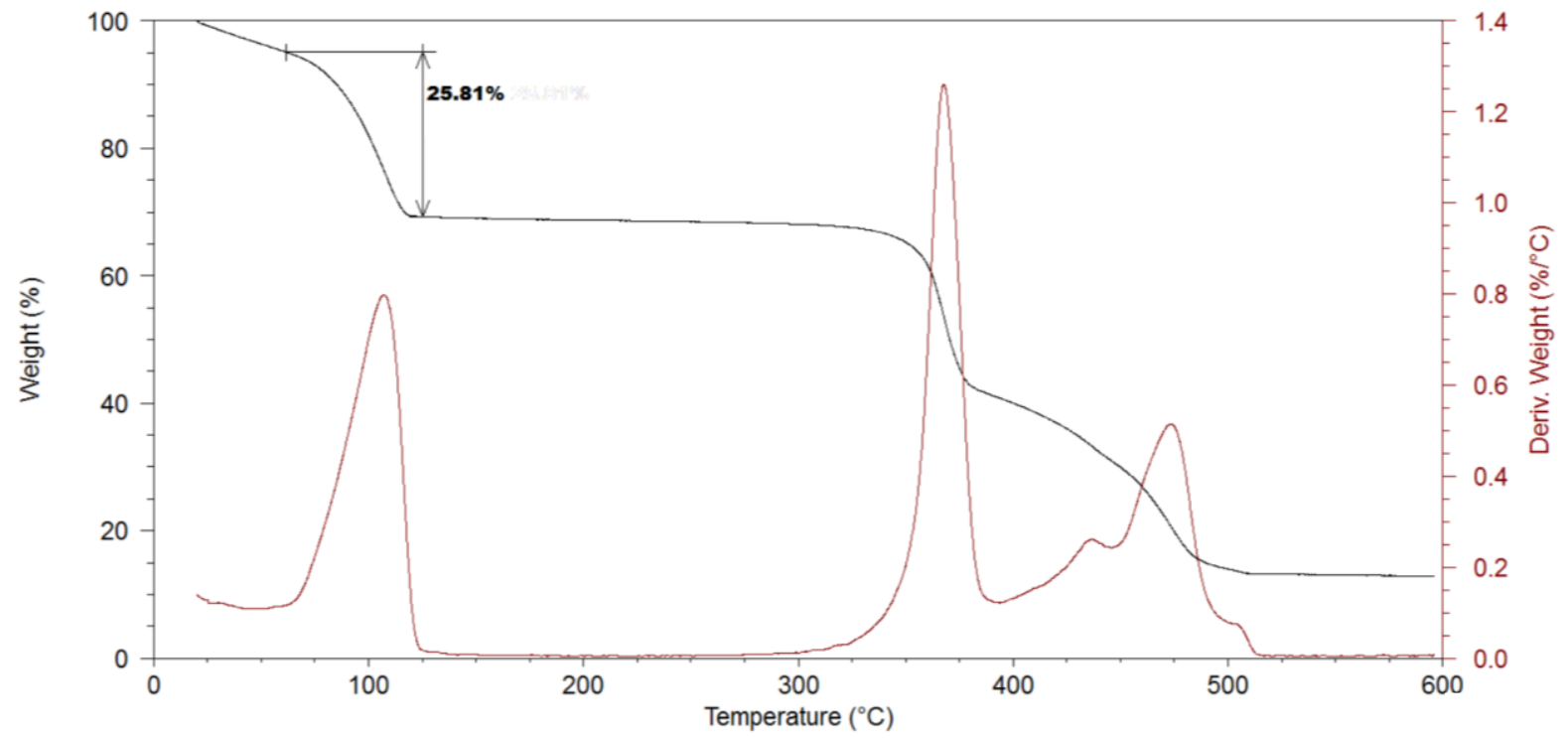

Figure S7: Thermogram of 1 . The weight loss of $25.8 \%$ is equal to ca 2 DMF molecules per ASU.

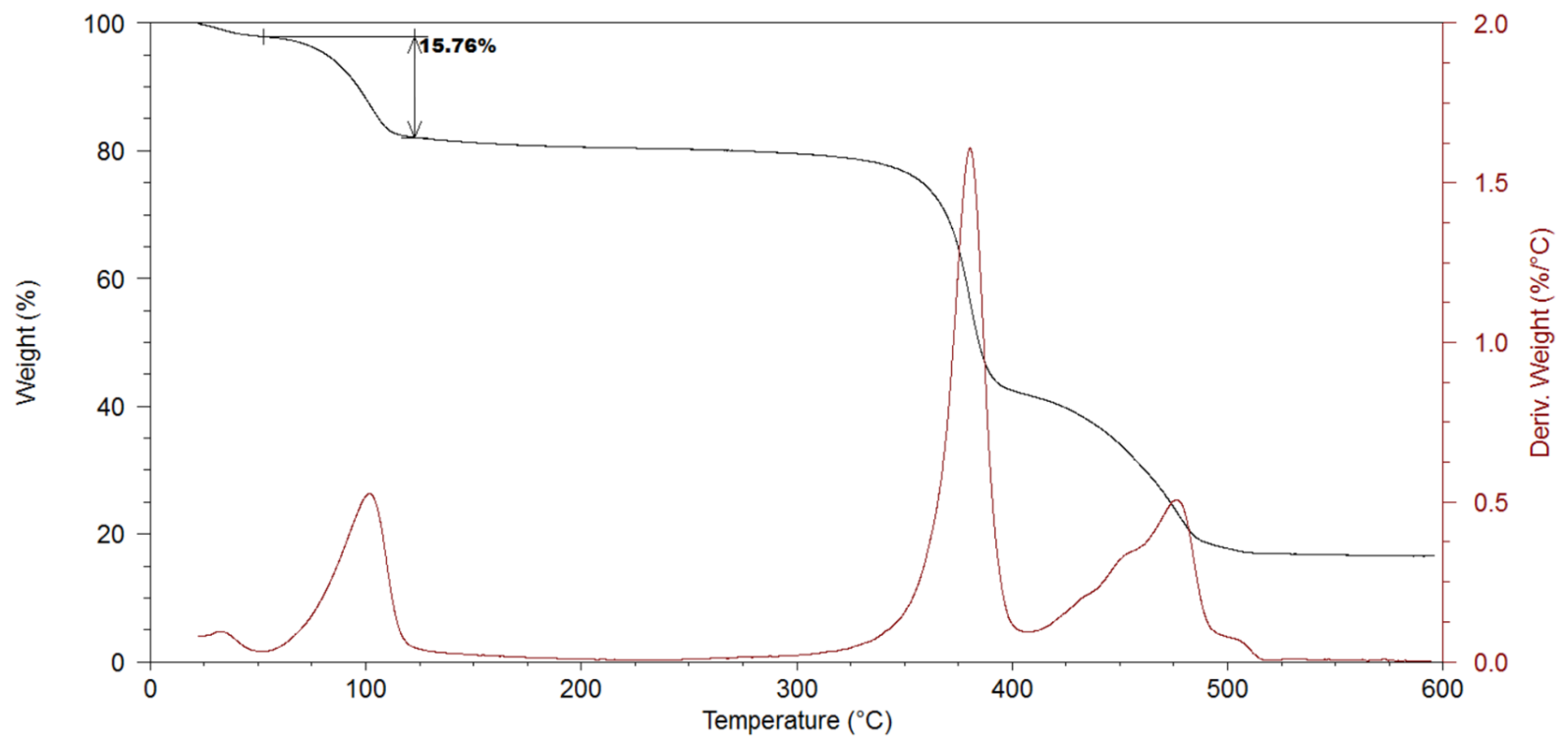

Figure S8: Thermogram of 2 . The weight loss of $15.8 \%$ is equal to ca 1 DMF molecule per ASU. 


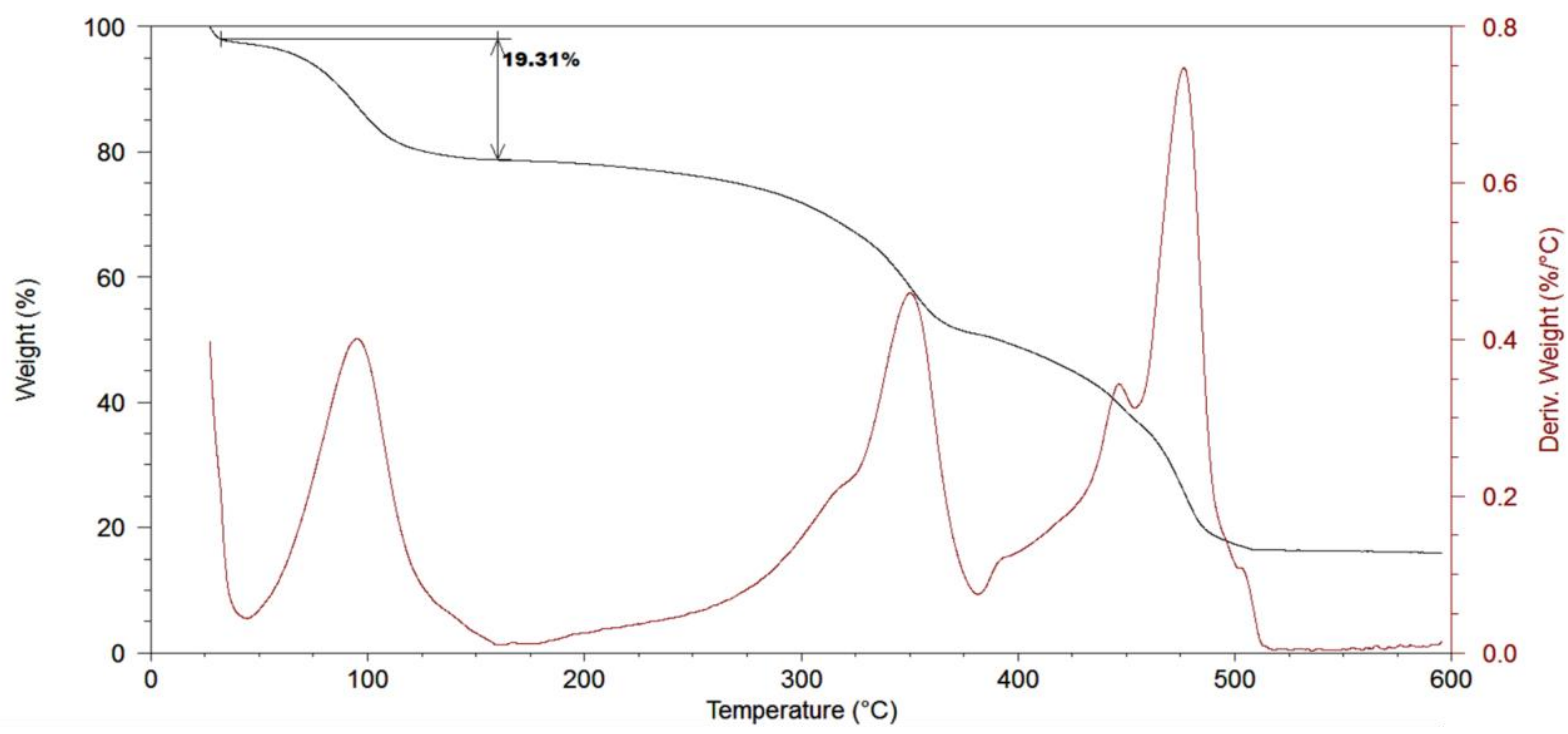

Figure S9: Thermogram of $1^{\prime}$. The weight loss of $19.3 \%$ is equal to ca 1.5 DMF molecules per ASU. This is less than in 1, however, once resolvated the material becomes paste-like in consistency making drying difficult. Rigorous drying to remove surface solvent may have resulted in the loss of a portion of the guest.

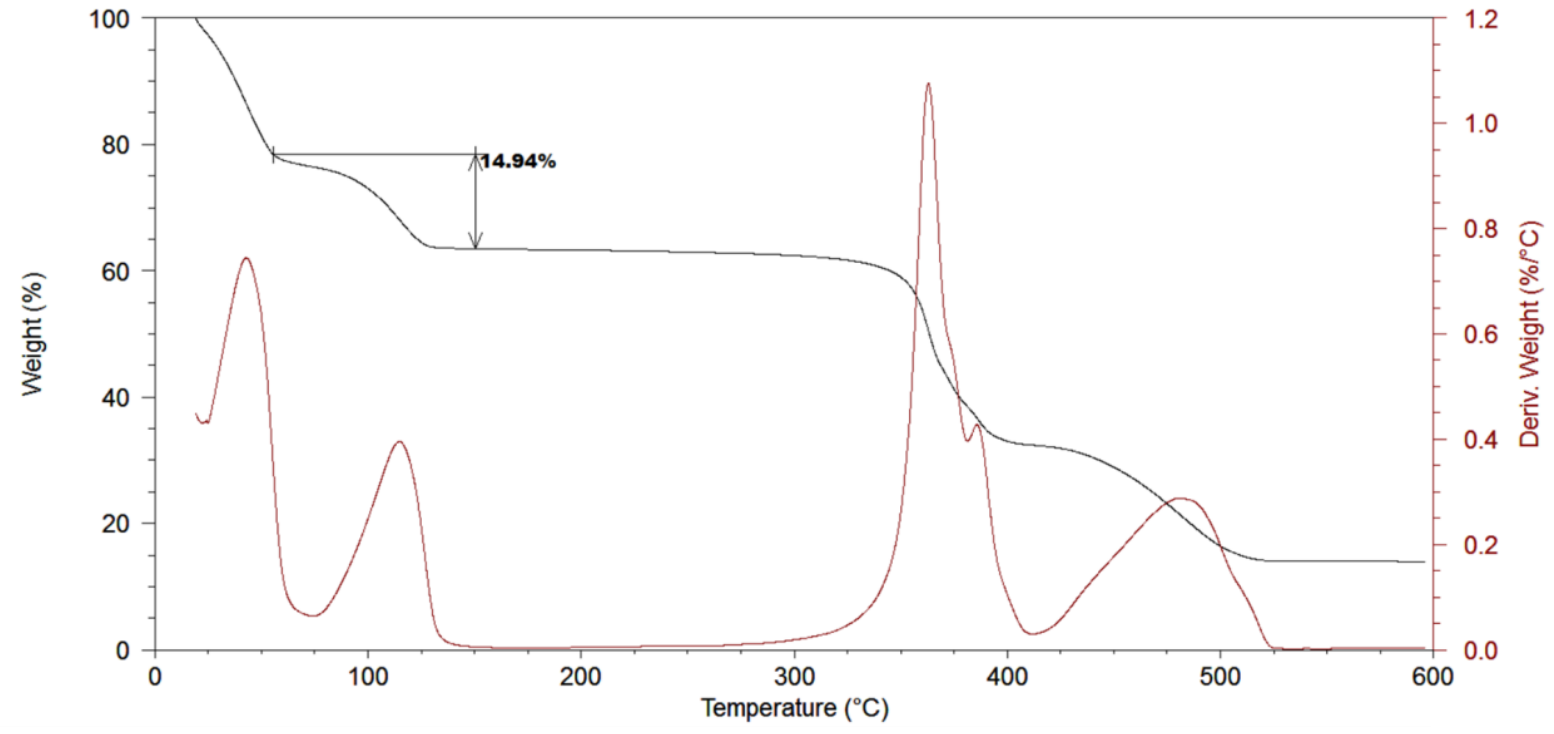

Figure S10: Thermogram of $2^{\prime}$. The weight loss of $14.9 \%$ is equal to ca 1 DMF molecule per ASU. Less rigorous drying of the resolvated paste resulted in a large surface solvent peak (onset to $c a 55^{\circ} \mathrm{C}$ ), however the guest occupancy matches well with that of 2 . 


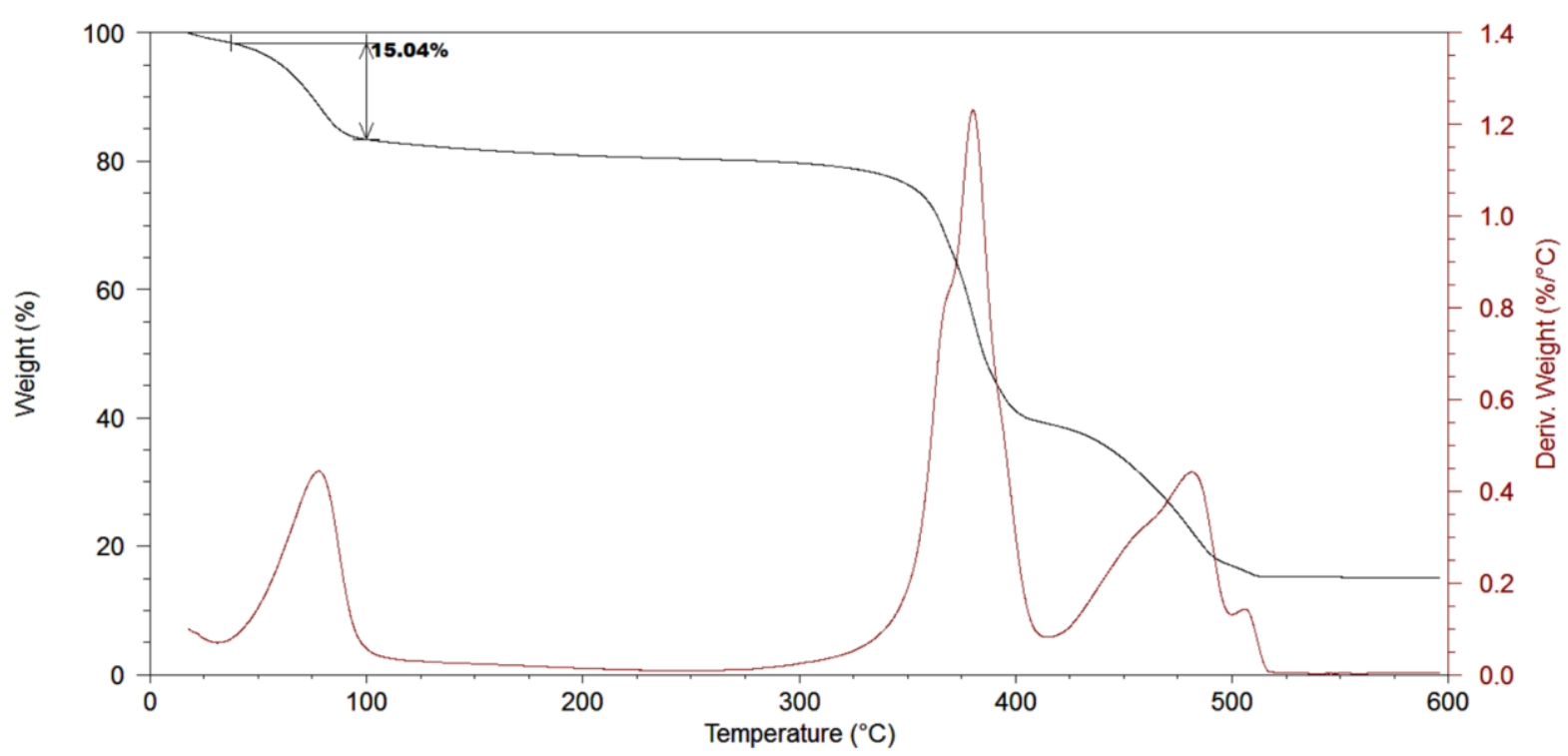

Figure S11: Thermogram of 2 after solvent exchange with THF. The weight loss of $15.0 \%$ is equal to ca 1 THF molecule per ASU.

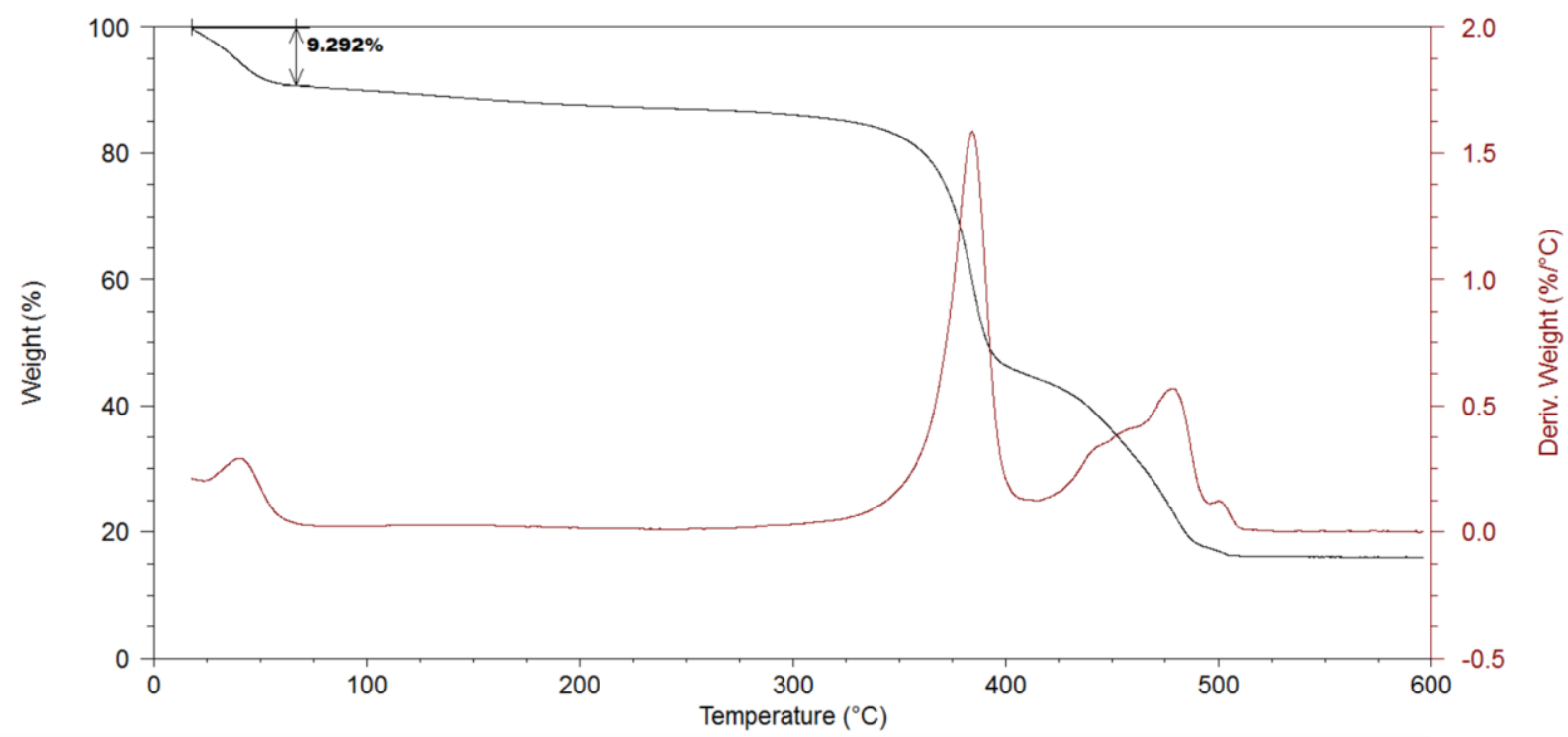

Figure S12: Thermogram of 2 after solvent exchange with DE. The weight loss of $9.3 \%$ is equal to ca 0.5 DE molecules per ASU. 


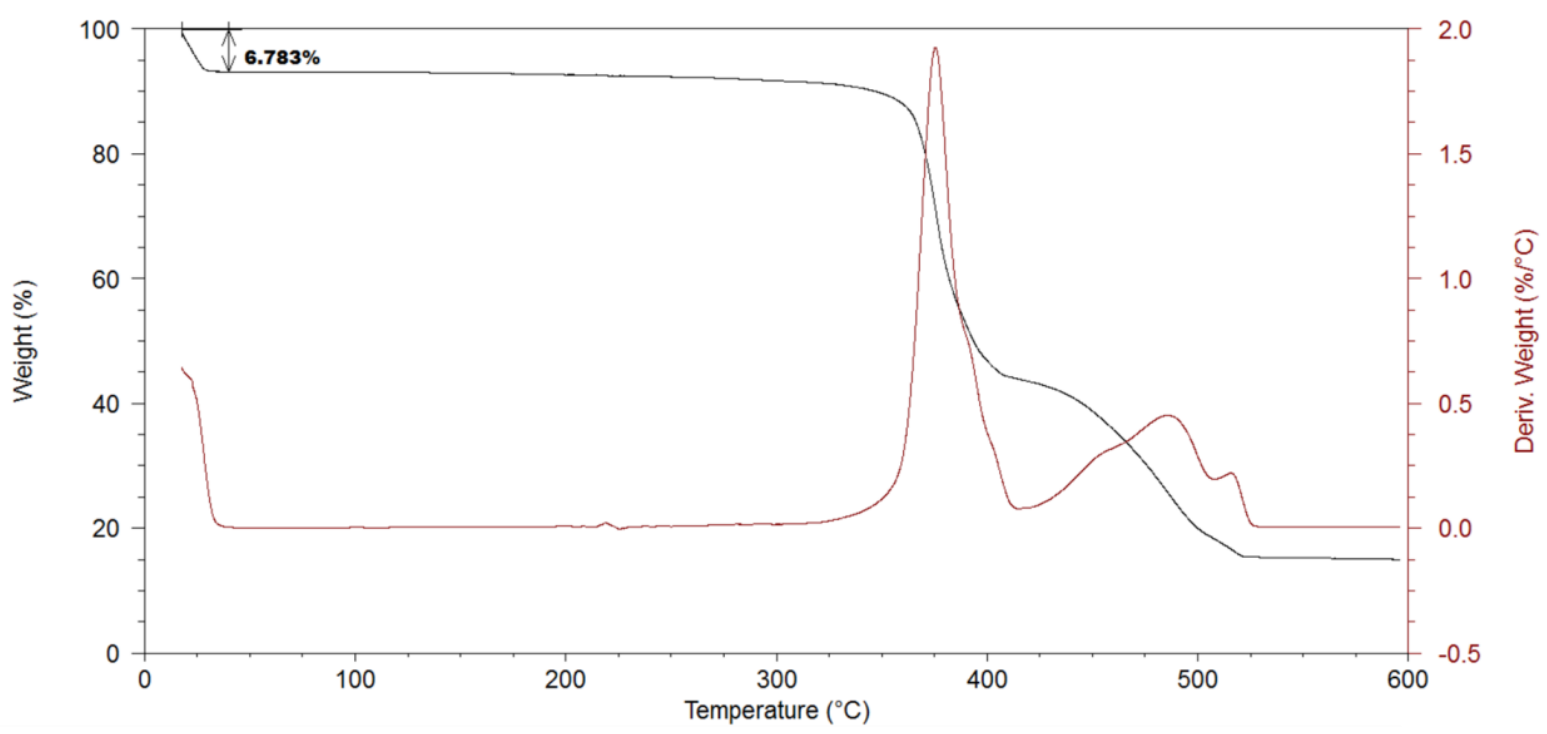

Figure S13: Thermogram of 2 after solvent exchange with $\mathrm{MeOH}$. The weight loss of $6.8 \%$ is equal to ca $1 \mathrm{MeOH}$ molecule per ASU.

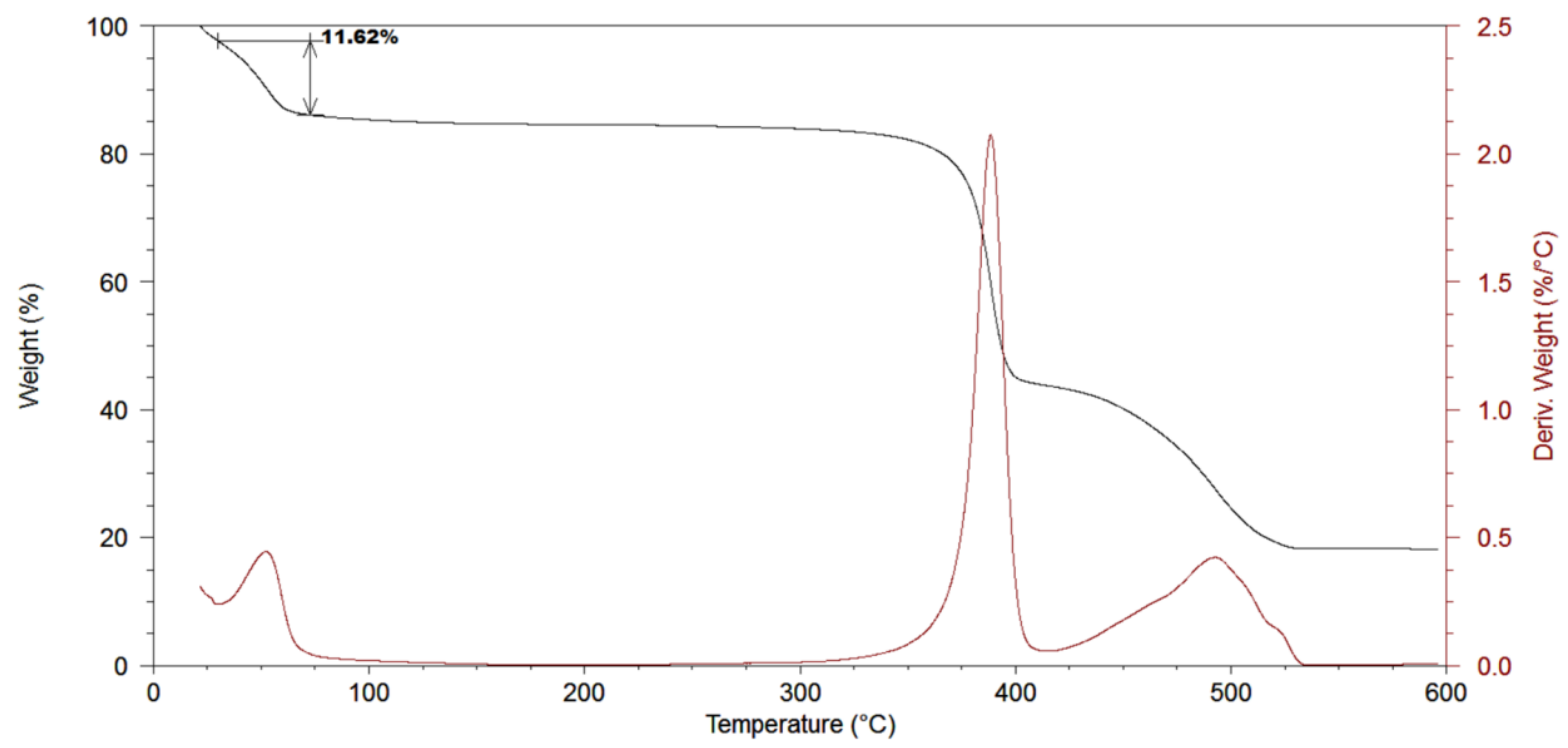

Figure S14: Thermogram of 2 after solvent exchange with EtOH. The weight loss of $11.6 \%$ is equal to ca $1 \mathrm{EtOH}$ molecule per ASU. 


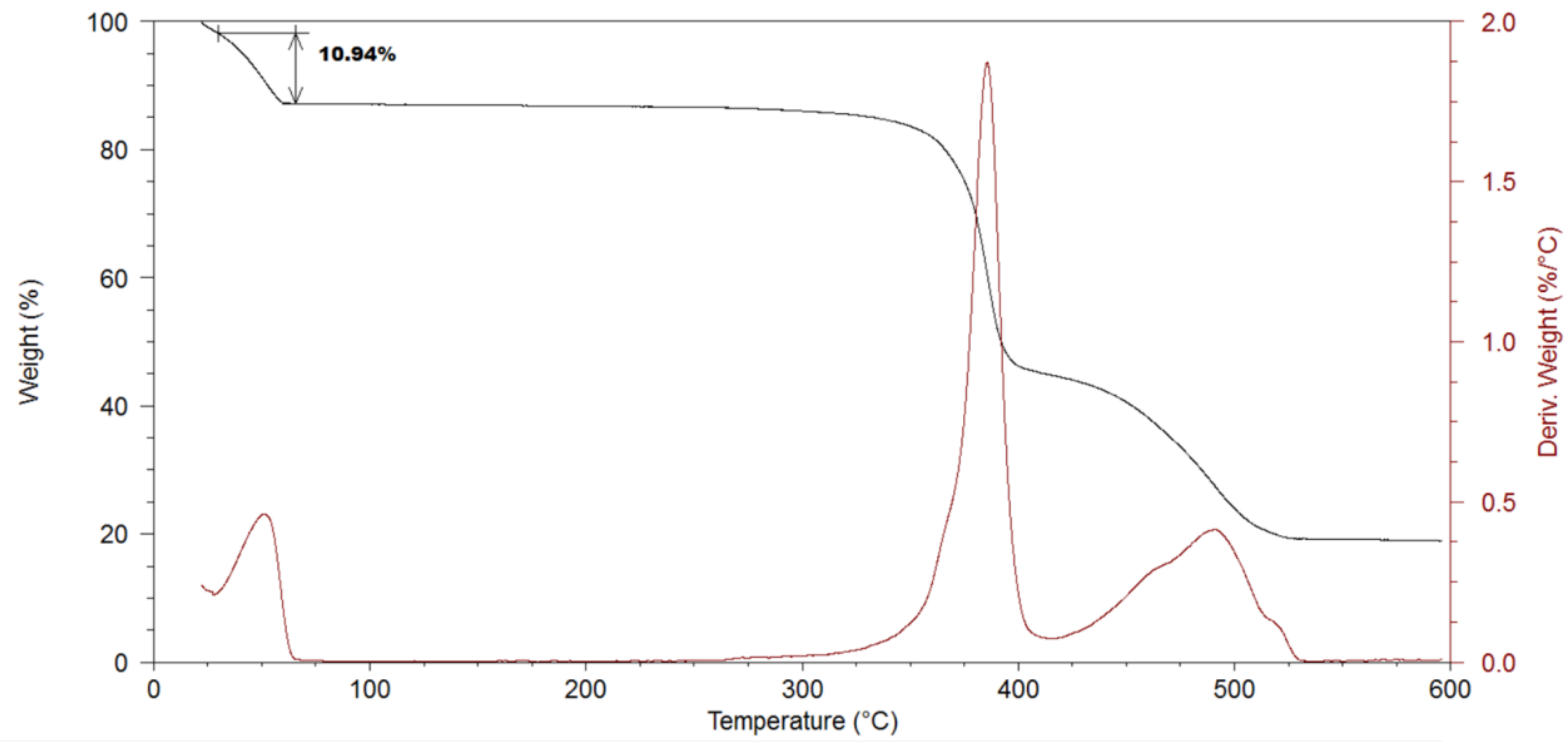

Figure S15: Thermogram of 2 after solvent exchange with ACN. The weight loss of $10.9 \%$ is equal to ca 1 ACN molecule per ASU.

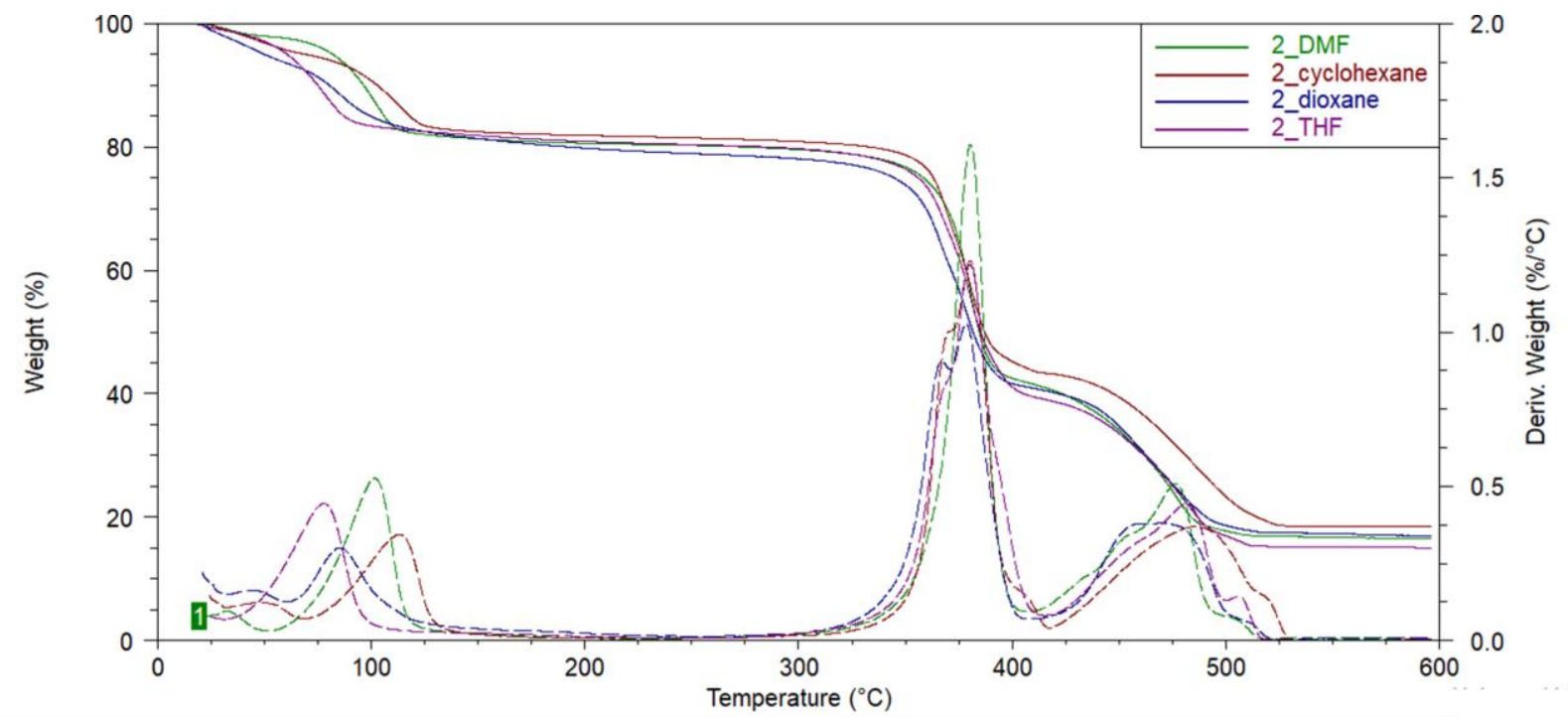

Figure S16: Thermograms of 2 (green trace) after solvent exchange with cyclohexane (red), 1,4dioxane (blue) and THF (purple). While the solvent exchange with THF is determined to be successful owing to the shift in the peak mass loss closer to the boiling point of THF and peak resolution. The attempted solvent exchanges with cyclohexane and 1,4-dioxane are ambiguous owing to their small peak shifts (event though their respective boiling points differ substantially from that of DMF) as well as the lack of peak resolution. 


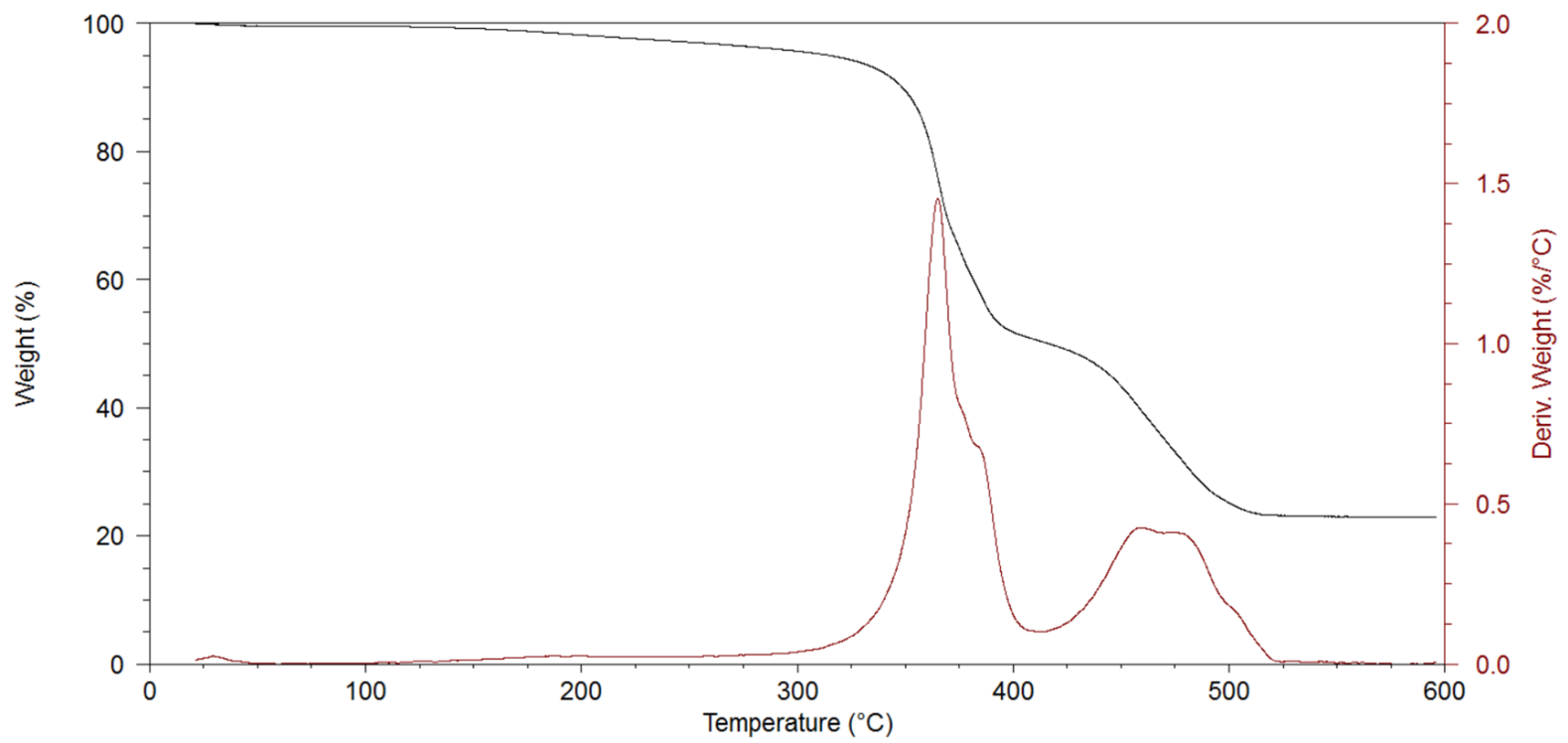

Figure S17: Thermogram of 2a post vapor sorption and heat treatment at $75{ }^{\circ} \mathrm{C}$ for several hours under reduced pressure.

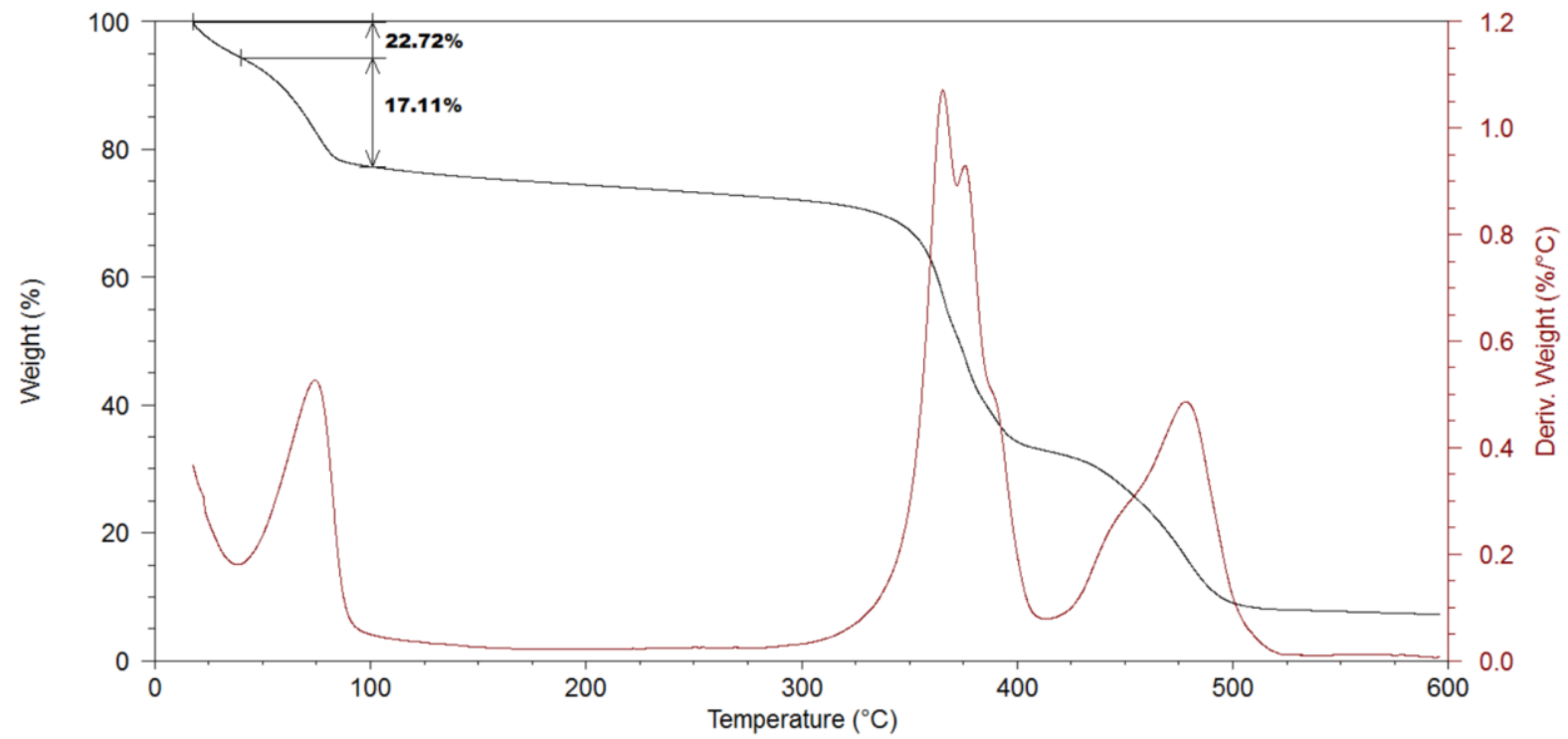

Figure S18: Thermogram of 2a post THF vapor sorption. The weight loss of $17.1 \%$ is equal to ca 1 THF molecule per ASU. However, the total initial weight loss of $c a 22.7 \%$ is equal to ca 1.6 molecules per ASU. This illustrates the effect of solvent condensation on the sample during vapor sorption. 


\section{Powder X-ray diffraction (PXRD)}

A Bruker D2 Phaser diffractometer was used to determine experimental diffractograms. The diffractometer utilises Bragg-Brentano geometry and $\mathrm{Cu}$ K $\alpha$ radiation $(\lambda=1.5418 \AA$ ) as the incident beam. The diffractometer was operated at $30 \mathrm{kV}$ and $10 \mathrm{~mA}$. Intensity data were recorded with a Lynxeye detector using a rotating flat stage $\left(30^{\circ} \mathrm{min}^{-1}\right)$. Samples were finely ground (where necessary) using a mortar and pestle, loaded onto a zero-background sample holder and levelled with a glass slide. The diffractograms were determined under ambient conditions with a scanning range of $5-40^{\circ}$, a step size of $0.016^{\circ}$ and a 0.8 second scan speed.

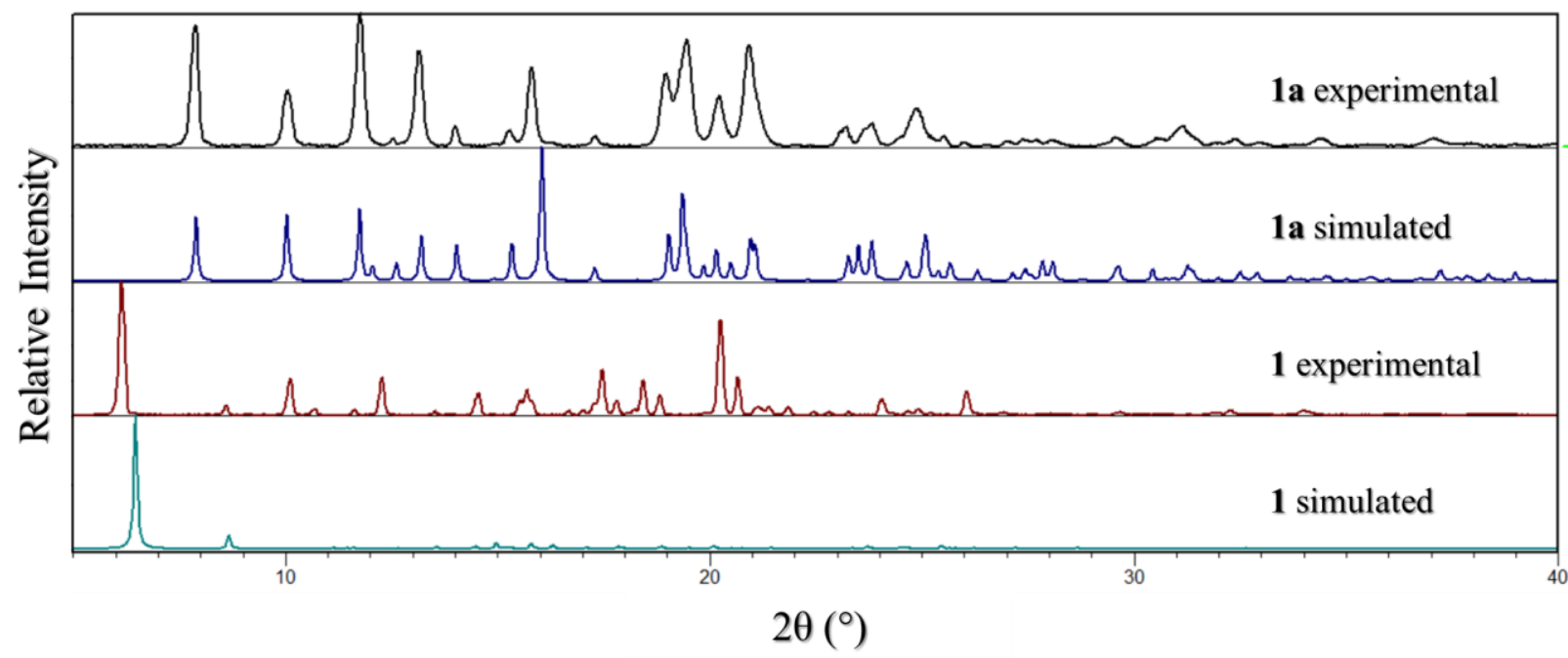

Figure S19: Diffractograms of 1 and 1a. The small shift between the simulated and experimental diffractograms of 1 may be attributed to thermal effects as the simulated diffractogram is generated from structural data collected at $100 \mathrm{~K}$.

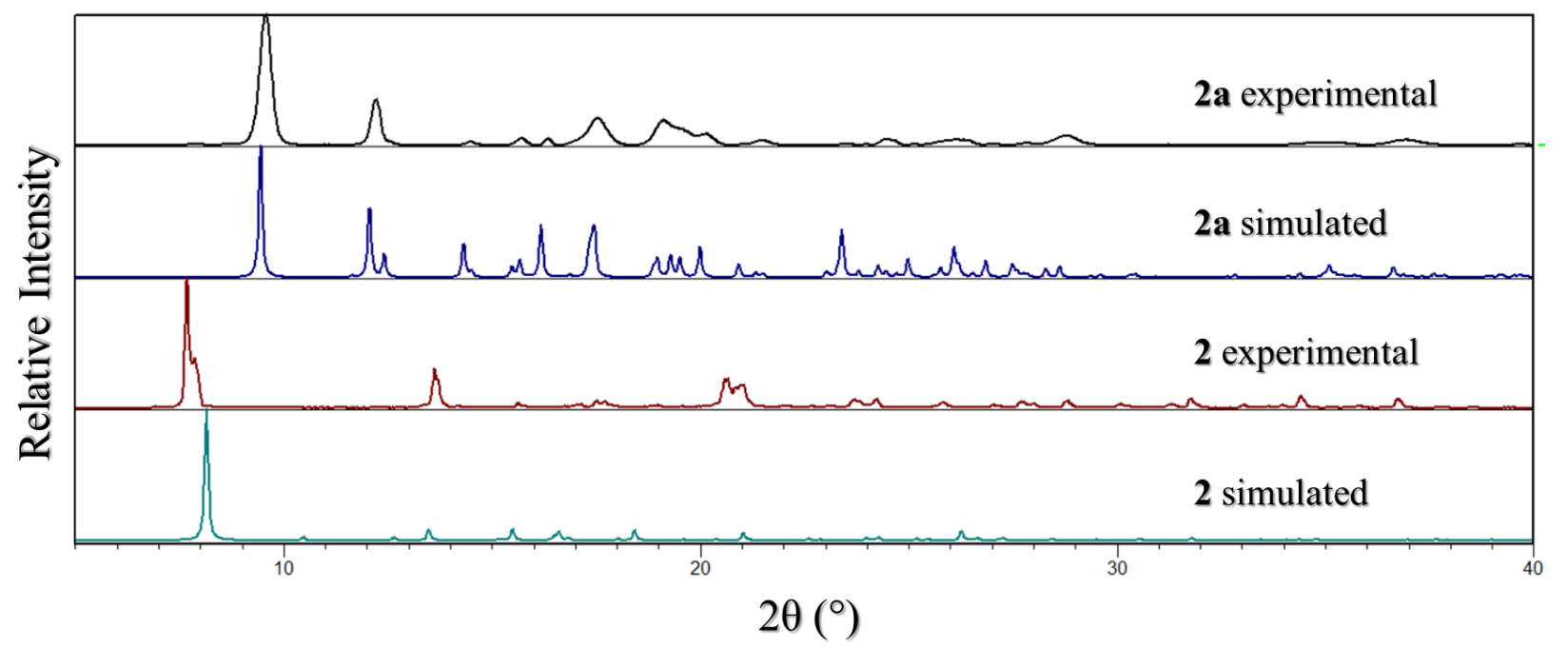

Figure S20: Diffractograms of 2 and 2a. The small shift between the simulated and experimental diffractograms of 2 may be attributed to thermal effects as the simulated diffractogram is generated from structural data collected at $100 \mathrm{~K}$. 


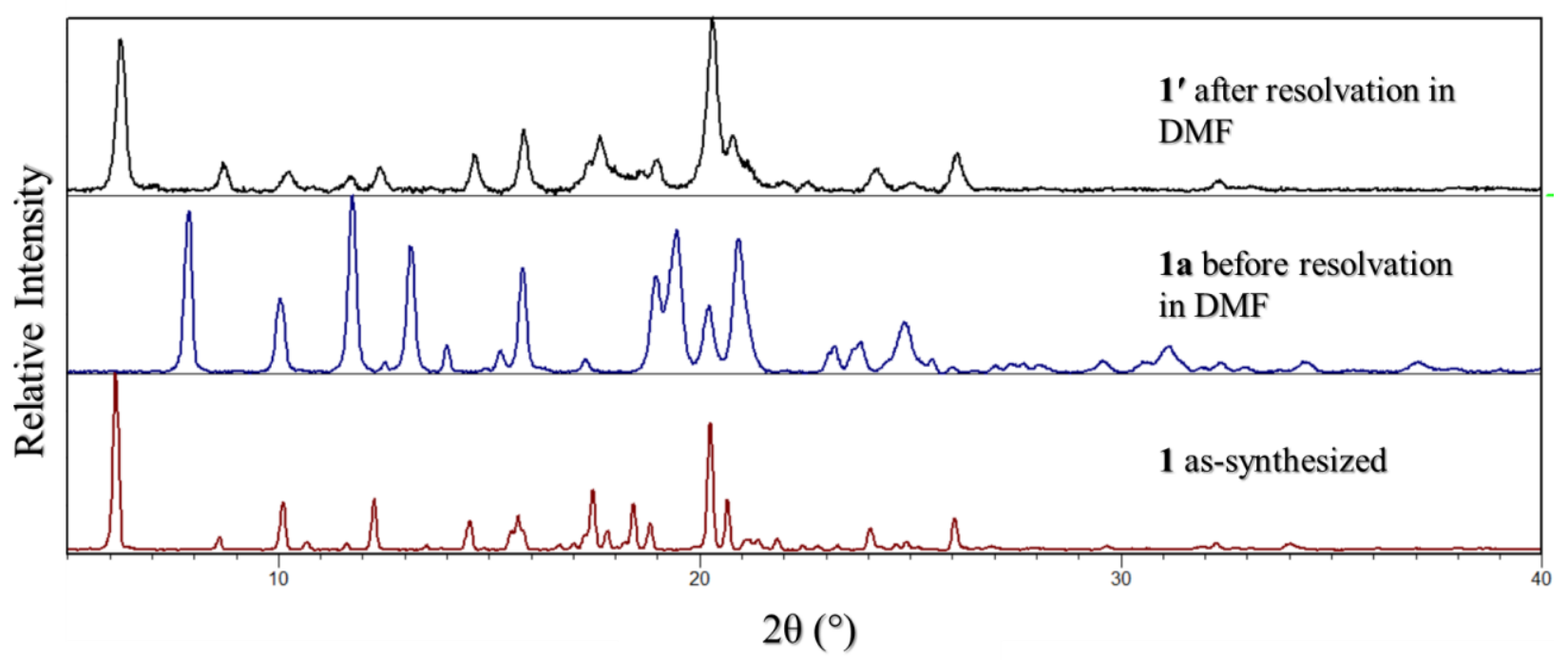

Figure S21: Experimental diffractograms of $1,1 \mathrm{a}$ and $\mathbf{1}^{\prime}$ (prepared by immersing 1a in DMF overnight).

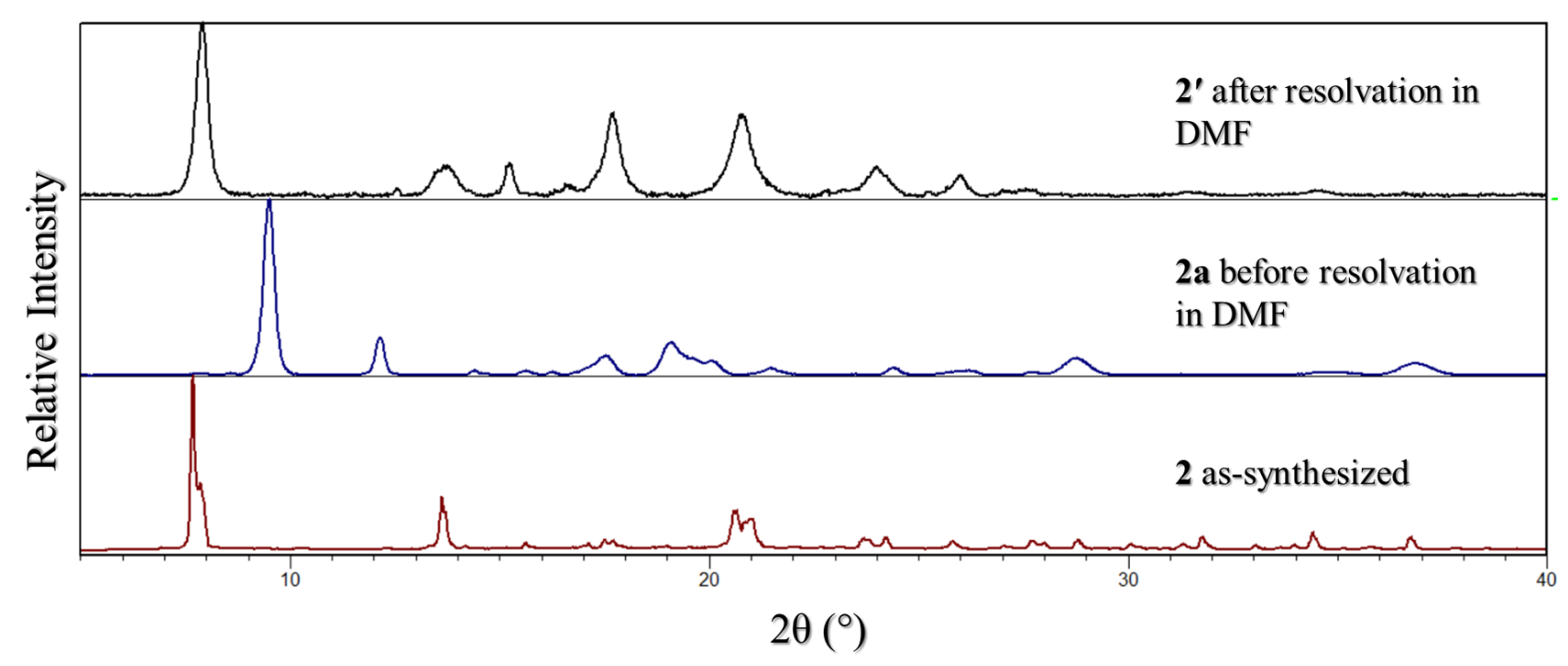

Figure S22: Experimental diffractograms of 2, 2a and 2' (prepared by immersing 2a in DMF overnight). 


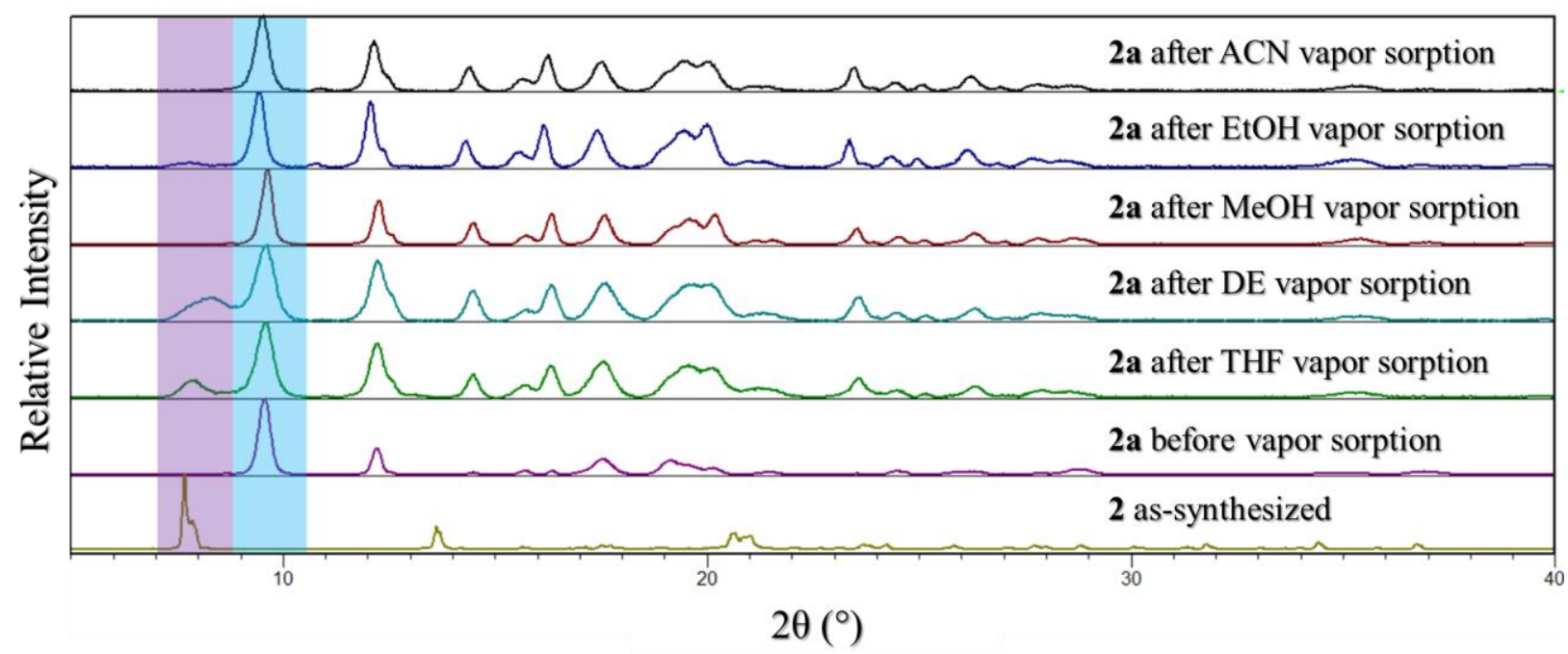

Figure S23: Experimental diffractograms of 2, 2a and 2a after each cycle of vapor sorption-desorption. The purple area highlights peaks which are characteristic of an open phase, while the blue area highlights those of a closed phase.

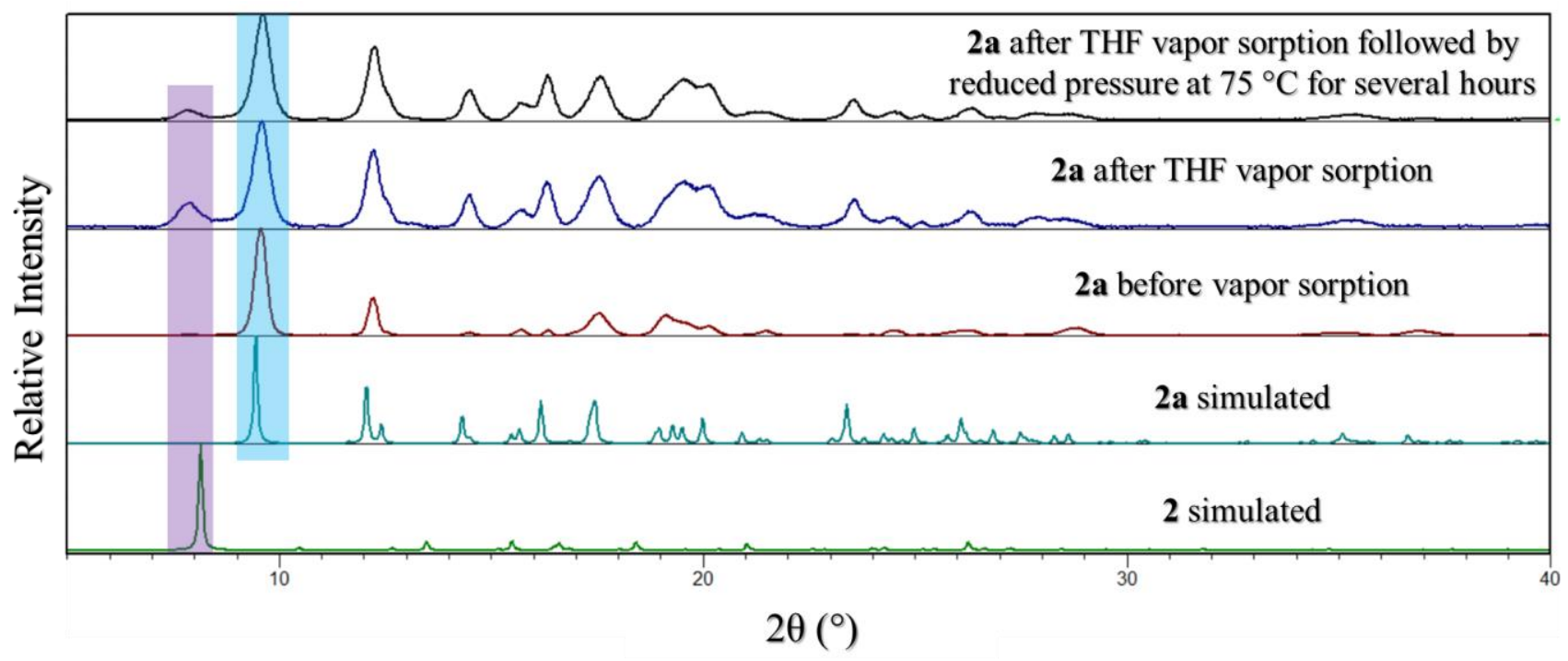

Figure S24: Experimental and simulated diffractograms of 2 and $2 a$, along with those of $2 a$ after THF vapor sorption-desorption and subsequent heat treatment. The purple area highlights peaks which are characteristic of an open phase, while the blue area highlights those of a closed phase. 


\section{Pressure Gradient Differential Scanning Calorimetry (PG-DSC)}

This set-up measures the change in heat flow of the sample as a function of pressure. PG-DSC experiments were carried out on a Setaram MDSC7 Evo instrument equipped with a high pressure sample holder (that can withstand up to 1000 bar). A Teledyne ISCO 260D syringe pump coupled to a D-series pump controller was used to increase the pressure throughout the measurement. ISCO software developed by Prof. L. J. Barbour was used to control the pressure gradient. Calisto Data Acquisition software was used to record the data. Calisto Processing software was used to process the raw data before plotting. A graphic representation of this set-up is shown in Figure $\$ 25 .{ }^{15,16}$

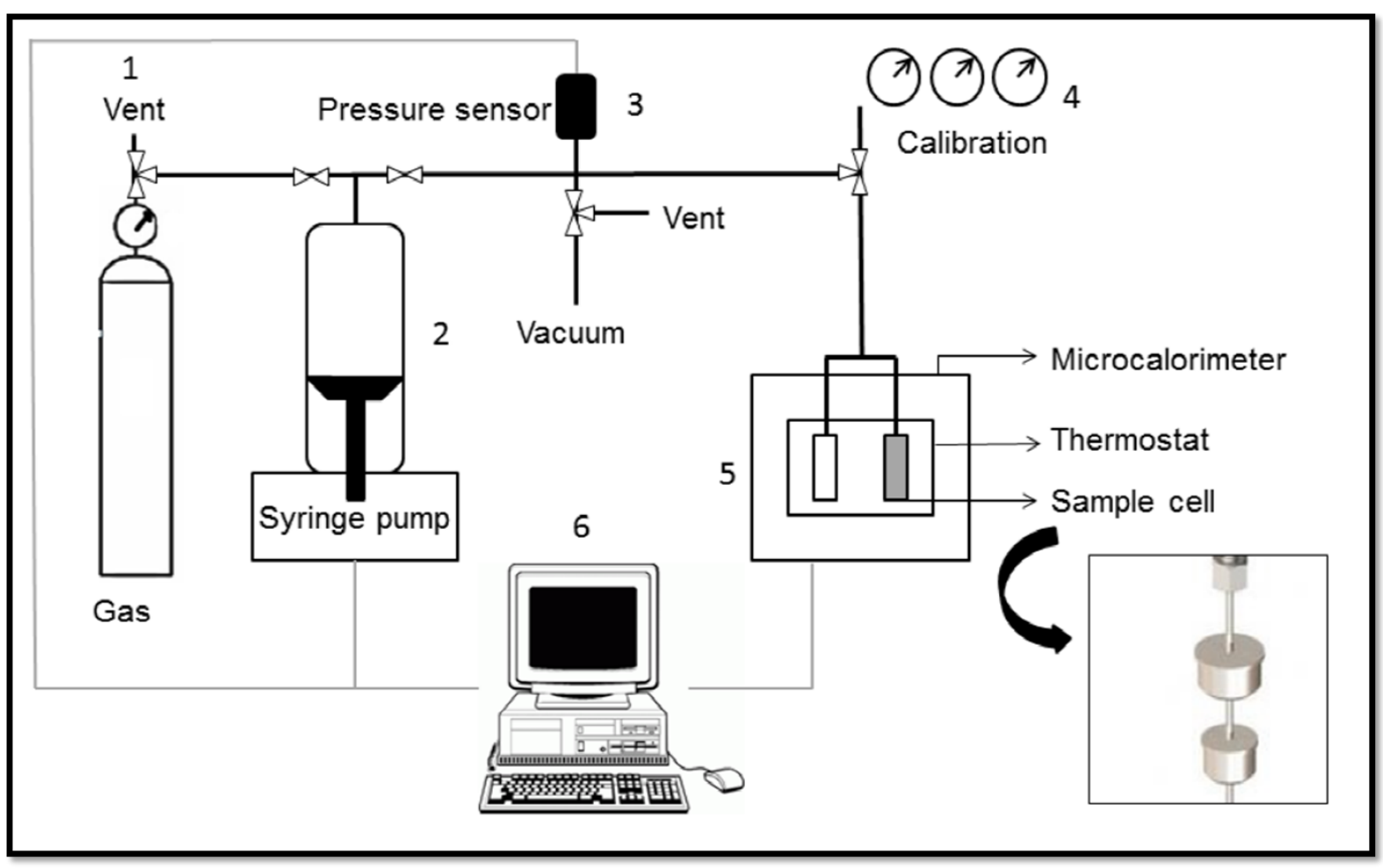

Figure S25: Diagrammatic representation of the PG-DSC instrumentation set-up. Numbers represent key structures: 1 - gas inlet, 2 - Teledyne ISCO 260D syringe pump, 3 - pressure sensor, 4 - calibration gauges, 5 - Setaram $\mu \mathrm{DSC} 7$ Evo and 6 - computer. ${ }^{15}$

Samples were activated in-situ under dynamic vacuum overnight (approximately 12 hours) to ensure the absolute activation. The vacuum pressure reached was $6.97 \times 10^{-2} \mathrm{mbar}$. After each cycle the samples were activated under the same conditions for ca. 1-2 hours. The initial pressure is required to be slightly higher than the desired starting pressure as the pressure may drop slightly once the sample valve is opened owing to the void volume of the system lines. Once the pressure and temperature were set, the sample was exposed to the pre-set pressure by opening the sample valve. The sample was then left to equilibrate for $c a$. 15-30 minutes. Thereafter the manual flow-rate program was started once the heat flow 
baseline was stable. After program completion, the sample was left for a further 10 minutes to return to its original equilibrium point, after which an activation cycle was initiated.

In materials that undergo phase changes to accommodate gaseous guests a peak is expected in the heat flow during the PG-DSC measurement. This heat flow peak subsequently corresponds to an inflection in the corresponding gas sorption isotherm. Since $1 \mathrm{a}$ and $2 \mathrm{a}$ are 'virtually nonporous' a phase change is indeed expected in order for sorption to take place. Since no peaks were observed in the PG-DSC experiments, no phase changes occurred over the pressure range for the gases trialled, and it may be inferred that no sorption occurred.

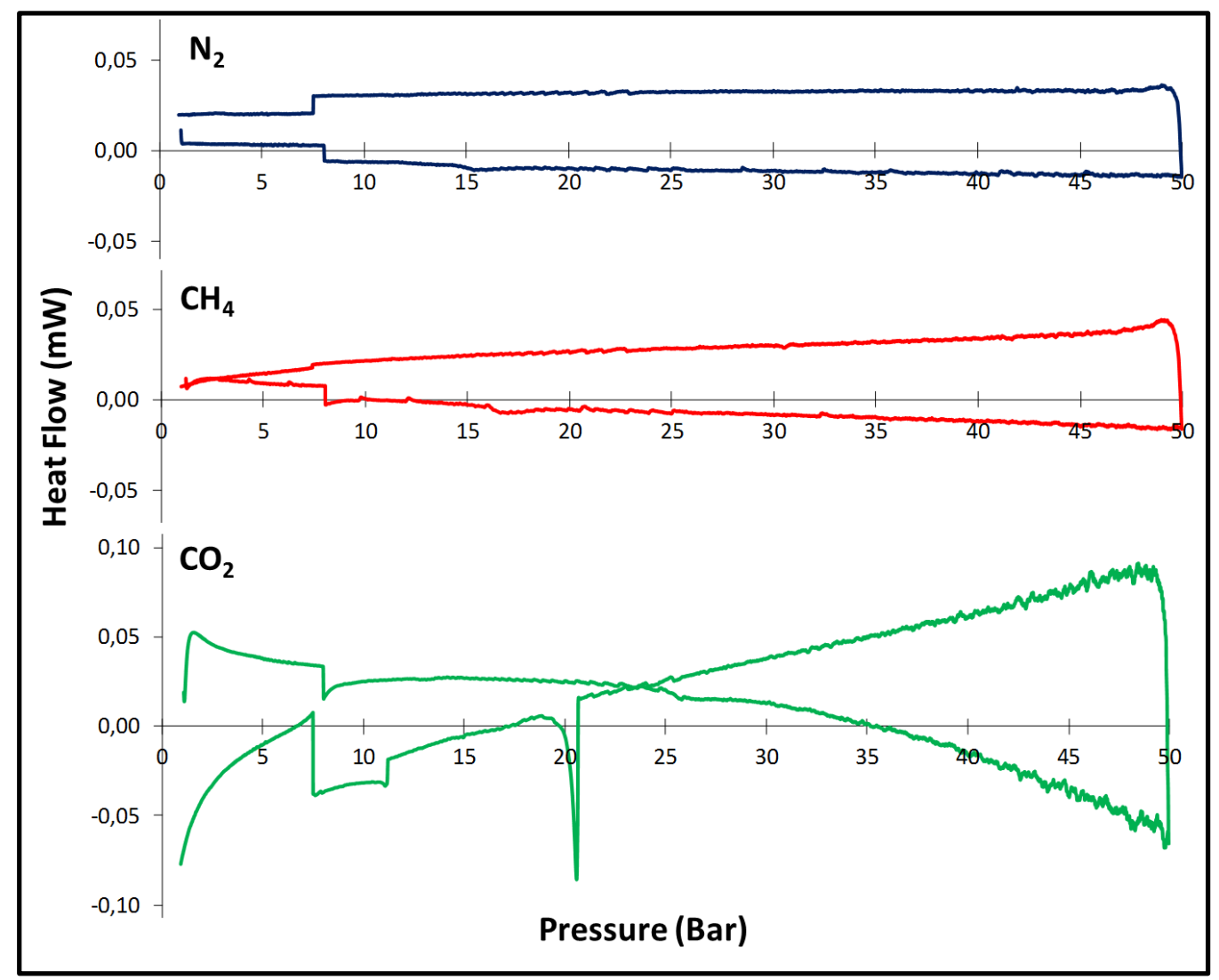

Figure S26: PG-DSC plots of 1a with $\mathrm{N}_{2}$ (blue), $\mathrm{CH}_{4}$ (red) and $\mathrm{CO}_{2}$ (green). Although there appears to be a peak around 20 bar $\mathrm{CO}_{2}$ (desorption), one should not the small scale of the plot. 


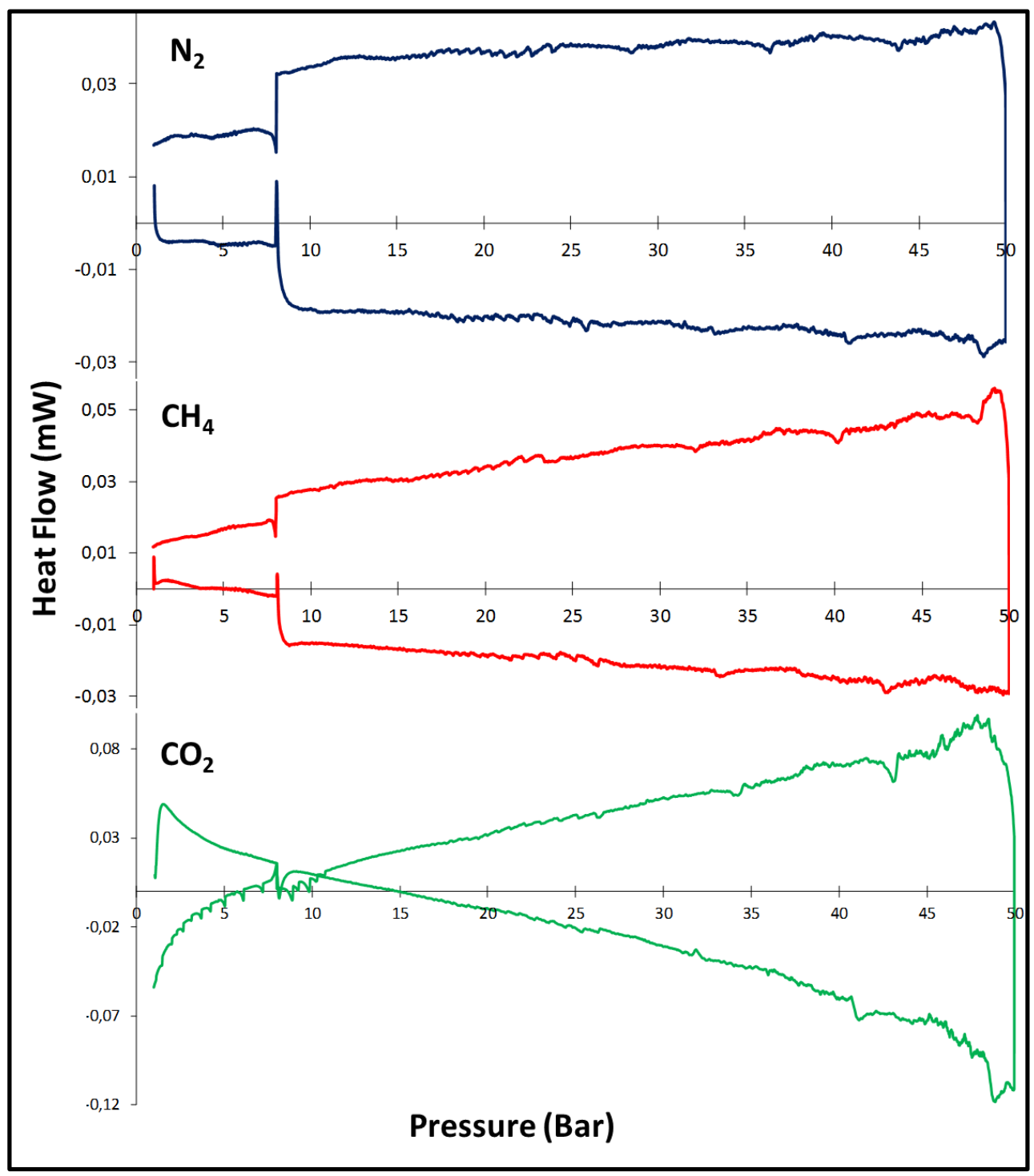

Figure S27: PG-DSC plots for 2 a with $\mathrm{N}_{2}$ (blue), $\mathrm{CH}_{4}$ (red) and $\mathrm{CO}_{2}$ (green).

\section{Vapor sorption}

A modified version of the vapor balance setup reported by Barbour and co-workers ${ }^{17}$ was used to carry out vapor sorption experiments. The system provides an accurate measure of the change in sample weight as a function of time. A wooden cabinet encloses the system to aid temperature regulation, in addition to two Edison light bulbs and an integral fan. The sample is suspended by a thin steel wire in an aluminum basket from the microelectronic balance with a counterweight suspended on the adjacent end. A vacuum pump and pressure sensor allow the system to be placed under reduced pressure $(0.1 \mathrm{mbar})$. This reduced pressure environment allows both for the preparation of the sample vapor along with the evacuation of the apparatus and sample after an experiment is complete. Typically sample 
sizes range from $15-30 \mathrm{mg}$, and the temperature is maintained at $23^{\circ} \mathrm{C}$. After introduction of the sample vapor to the system the experiment is allowed to run until the sample weight reaches a plateau (indicating an equilibrium state). When required, the desorption profile can also be recorded by applying reduced pressure to a sorbed system at equilibrium. Once more the experiment is continued until an equilibrium state was reached.
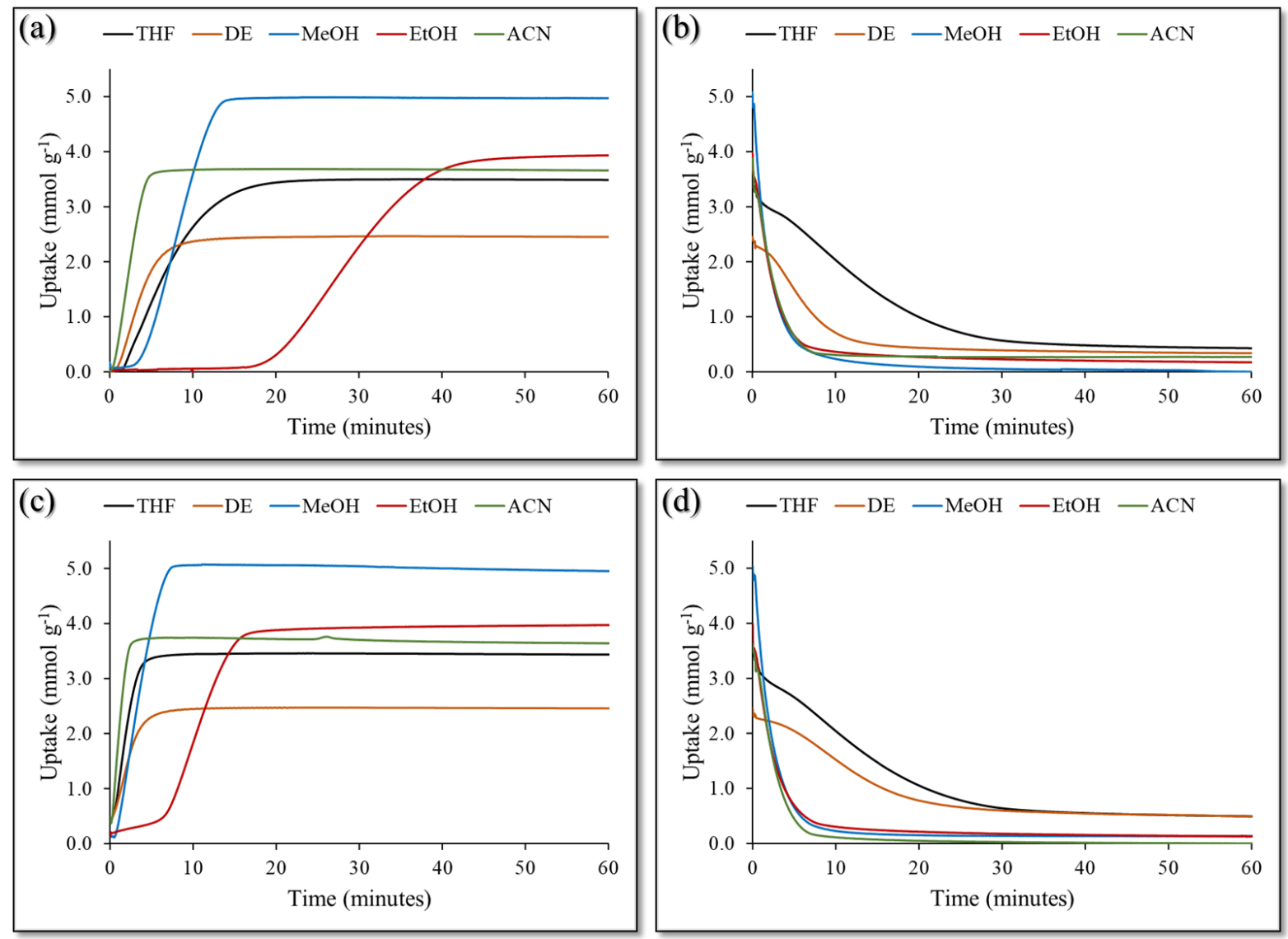

Figure S28: Vapor adsorption (left) and desorption (right) profiles for $\mathbf{2 a}$. Two sorption-desorption cycles were carried out consecutively. Cycle 1 is shown in (a) and (b), and cycle 2 in (c) and (d). 


\section{Vapor pressures and kinetic diameters of select solvents}

Table S5. Vapor pressures of select solvents calculated from the Antoine equation. 18,19

\begin{tabular}{|c|c|c|}
\hline Solvent & $\begin{array}{c}\text { Vapor pressure at } 20^{\circ} \mathrm{C} \\
\text { (mbar) }\end{array}$ & $\begin{array}{c}\text { Vapor pressure at } 25^{\circ} \mathrm{C} \\
\text { (mbar) }\end{array}$ \\
\hline THF & $\mathrm{T}^{2} \mathrm{~T}_{\min }$ & 216 \\
$\mathrm{DE}$ & 583 & 710 \\
$\mathrm{MeOH}$ & 130 & 169 \\
$\mathrm{EtOH}$ & 58 & 78 \\
$\mathrm{ACN}$ & 97 & 122 \\
\hline
\end{tabular}

Table S6. Kinetic diameters of select solvents.

\begin{tabular}{|c|c|}
\hline Solvent & Kinetic diameter $(\AA)$ \\
\hline 1,4-dioxane & $7.0^{20}$ \\
p-xylene & $6.5^{21}$ \\
toluene & $5.9^{21}$ \\
DE & $5.2^{22,23}$ \\
THF & $4.9^{22,23}$ \\
EtOH & $4.3^{22,23}$ \\
ACN & $4.3^{22,23}$ \\
MeOH & $3.8^{22,23}$ \\
\hline
\end{tabular}

\section{References}

(1) MiTeGen. MiTeGen https://www.mitegen.com/ (accessed Jun 25, 2018).

(2) Bruker AXS Inc. SAINT Data Collection Software. Bruker AXS Inc.: Madison, WI 2016.

(3) Bruker AXS Inc. SADABS Data Correction Software. Bruker AXS Inc.: Madison, WI 2016.

(4) Sheldrick, G. M. SHELXT - Integrated Space-Group and Crystal-Structure Determination. Acta Cryst. 2015, A71, 3-8.

(5) Sheldrick, G. M. Crystal Structure Refinement with SHELXL. Acta Cryst. 2015, C71, 3-8.

(6) Barbour, L. J. X-Seed - A Software Tool for Supramolecular Crystallography. J. Supramol. Chem. 2001, 1 (4-6), 189-191. https://doi.org/10.1016/S1472-7862(02)00030-8.

(7) Barbour, L. J. X-Seed 4: Updates to a Program for Small-Molecule Supramolecular 
Crystallography. J. Appl. Cryst. 2020, 53, 1-6.

https://doi.org/10.1107/S1600576720007438.

(8) Persistence of Vision Raytracer Pty. Ltd. POV-Ray for Windows. Persistence of Vision Raytracer Pty. Ltd.: Williamstone 2004.

(9) Macrae, C. F.; Edgington, P. R.; McCabe, P.; Pidcock, E.; Shields, G. P.; Taylor, R.; Towler, M.; Van De Streek, J. Mercury: Visualization and Analysis of Crystal Structures. J. Appl. Crystallogr. 2006, 39 (3), 453-457. https://doi.org/10.1107/S002188980600731X.

(10) Macrae, C. F.; Bruno, I. J.; Chisholm, J. A.; Edgington, P. R.; McCabe, P.; Pidcock, E.; Rodriguez-Monge, L.; Taylor, R.; Van De Streek, J.; Wood, P. A. Mercury CSD 2.0 - New Features for the Visualization and Investigation of Crystal Structures. J. Appl. Crystallogr. 2008, 41 (2), 466-470. https://doi.org/10.1107/S0021889807067908.

(11) MacRae, C. F.; Sovago, I.; Cottrell, S. J.; Galek, P. T. A.; McCabe, P.; Pidcock, E.; Platings, M.; Shields, G. P.; Stevens, J. S.; Towler, M.; Wood, P. A. Mercury 4.0: From Visualization to Analysis, Design and Prediction. J. Appl. Crystallogr. 2020, 53, 226-235. https://doi.org/10.1107/S1600576719014092.

(12) Spek, A. L. PLATON SQUEEZE: A Tool for the Calculation of the Disordered Solvent Contribution to the Calculated Structure Factors. Acta Crystallogr. 2015, C71, 9-18. https://doi.org/10.1107/S2053229614024929.

(13) van Heerden, D. P.; Barbour, L. J. Guest-Occupiable Space in the Crystalline Solid State: A Simple Rule-of-Thumb for Predicting Occupancy. Chem. Soc. Rev. 2021, 50 (2), 735749. https://doi.org/10.1039/d0cs01040e.

(14) Groom, C. R.; Bruno, I. J.; Lightfoot, M. P.; Ward, S. C. The Cambridge Structural Database. Acta Crystallogr. 2016, B72 (2), 171-179. https://doi.org/10.1107/S2052520616003954.

(15) White, K.-A. Direct Determination of Isosteric Heats of Sorption Using PressureGradient Differential Scanning Calorimetry, University of Stellenbosch, 2017.

(16) Feldmann, W. K.; White, K.-A.; Bezuidenhout, C. X.; Smith, V. J.; Esterhuysen, C.; Barbour, L. J. Direct Determination of Enthalpies of Sorption Using Pressure-Gradient Differential Scanning Calorimetry: CO2 Sorption by Cu-HKUST. ChemSusChem 2020, 13 
(1), 102-105. https://doi.org/https://doi.org/10.1002/cssc.201902990.

(17) Barbour, L. J.; Achleitner, K.; Greene, J. R. A System for Studying Gas-Solid in Controlled Atmospheres Reaction Kinetics. Thermochim. Acta 1992, 5 (205), 171-177.

(18) Dortmund Data Bank. Saturated Vapor Pressure http://ddbonline.ddbst.com/AntoineCalculation/AntoineCalculationCGl.exe (accessed Mar 28, 2019).

(19) Rodgers, R. C. M. D.; Hill, G. E. M. D. EQUATIONS FOR VAPOUR PRESSURE VERSUS TEMPERATURE : DERIVATION AND USE OF THE ANTOINE EQUATION ON A HAND-HELD PROGRAMMABLE CALCULATOR. Br. J. Anaesth. 1978, 50 (5), 415-424. https://doi.org/10.1093/bja/50.5.415.

(20) Bhat, S. D.; Aminabhavi, T. M. Novel Sodium Alginate Composite Membranes Incorporated with SBA-15 Molecular Sieves for the Pervaporation Dehydration of Aqueous Mixtures of Isopropanol and 1,4-Dioxane at $30^{\circ} \mathrm{C}$. Microporous Mesoporous Mater. 2006, 91 (1-3), 206-214. https://doi.org/10.1016/j.micromeso.2005.11.044.

(21) Fairén-Jiménez, D.; Carrasco-Marín, F.; Moreno-Castilla, C. Adsorption of Benzene, Toluene, and Xylenes on Monolithic Carbon Aerogels from Dry Air Flows. Langmuir 2007, 23 (20), 10095-10101. https://doi.org/10.1021/la701458h.

(22) Bowen, T. C.; Li, S.; Noble, R. D.; Falconer, J. L. Driving Force for Pervaporation through Zeolite Membranes. J. Memb. Sci. 2003, 225 (1-2), 165-176.

https://doi.org/10.1016/j.memsci.2003.07.016.

(23) Leeuwen, M. E. Van. Derivation of Stockmayer Potential Parameters. Fluid Phase Equilib. 1994, 99 (94), 1-18. 